\title{
A DSM Test Case Applied on an End-to-End System, from Consumer to Energy Provider
}

\author{
Nikoleta Andreadou ${ }^{1, *}$, Yannis Soupionis ${ }^{2}$, Fausto Bonavitacola ${ }^{1}$ and Giuseppe Prettico ${ }^{1}$ \\ 1 Energy Security, Systems and Markets Unit, Directorate of Energy, Transport and Climate, \\ Joint Research Centre, 21027 Ispra, Italy; Fausto.BONAVITACOLA@ext.ec.europa.eu (F.B.); \\ Giuseppe.PRETTICO@ec.europa.eu (G.P.) \\ 2 Technology Innovation in Security Unit, Space, Directorate of Security and Migration, Joint Research Centre, \\ 21027 Ispra, Italy; Yannis.SOUPIONIS@ec.europa.eu \\ * Correspondence: nikoleta.andreadou@ec.europa.eu
}

Received: 1 February 2018; Accepted: 18 March 2018; Published: 23 March 2018

check for updates

\begin{abstract}
Current decarbonisation goals have, in recent years, led to a tremendous increase in electricity production generated from intermittent Renewable Energy Sources. Despite their contribution to reducing society's carbon dioxide $\left(\mathrm{CO}_{2}\right)$ emissions they have been responsible for numerous challenges that the current electricity grid has to cope with. Flexibility has become a key mechanism to help in mitigating them. Real-time informed consumers can offer the needed flexibility through modifying their behaviour or by engaging with Demand Side Management (DSM) programs. The latter requires the intervention of several actors and levels of communication management which makes this task difficult from an implementation perspective. With this aim we built and tested a small scale system in our lab which represents a real end-to-end system from the consumer to the energy provider. We programmed the system according to the Object Identification System (OBIS) specification to obtain consumers' consumption through smart meters with high frequency (one minute). This allows remote control of their appliances in order to reduce the total neighbourhood consumption during critical time periods of the day (peak time). These results and the realisation of a realistic end-to-end system open the way to more complex tests and particularly to the possibility of benchmarking them with other lab tests.
\end{abstract}

Keywords: Demand Side Management (DSM); Advanced Metering Infrastructure (AMI); End-to-End Testbed; Demand Response (DR); smart meter

\section{Introduction}

The traditional electricity grid is undergoing significant changes and is required to evolve in order to cope with the constantly growing technological and conceptual challenges that are emerging. The necessity to reduce $\mathrm{CO}_{2}$ emissions and the consequent requirement to accommodate an increasing number of intermittent Renewable Energy Sources (RES) into the current energy system call for an effective management of distributed energy production and also of consumption. Great advancements in Information and Communications Technology (ICT) can indeed allow the grid to be controlled, monitored, and to become more automatised. However, it is not just a technological problem. A new paradigm shift is in fact emerging, by which it would not be the energy supply following the demand, but rather the opposite [1]: when available, (renewable) energy must be consumed. This is reflected in the different hourly prices of electricity that are cleared daily in the wholesale market. Abundance of renewables usually considerably decreases such prices. Understanding how successful the potential shift of electricity consumption towards lower price periods could be, if households were informed about the real cost of electricity, is thus a key question to address. 
The concept of demand flexibility has hence naturally emerged in recent years in the electricity debate. It can be defined as the ability of the demand-side to adjust its consumption according to price signals that can inform final consumers about the scarcity/abundance of clean-thus cheap-electricity in the market or about actual congestions happening in the grid (e.g., peak time). Two different concepts have been conceived to refer to demand flexibility: Demand Response (DR) and Demand Side Management (DSM) [2]:

- Demand Response is considered to be the bottom-up approach: the customer is provided with incentives so as to become active in load management and to shift/curtail his/her loads. Such incentives can be convenient tariff schemes or economic benefits in general. In any case, the customer is responsible for managing his/her consumption. In DR end-users intentionally change their consumption habits, including the timing and level of consumption. Several approaches have been proposed so far in the different Member States of the European Union and many studies on tariffs are being carried out by National Regulators [3,4].

- Demand Side Management is usually considered, instead, a top-down approach: the energy provider/energy service company/aggregator is responsible for reducing or removing peak loads. Such an actor decides on which measures to be undertaken based on the established agreements with the final customers so as to increase the grid's stability. DSM is not a novel concept and has been used in the past by system operators to disconnect big electricity consumers (e.g., industries), in cases of energy outages in a specific geographical area or for specific peak time hours. Nowadays smart grids can offer a more sophisticated and effective way of DSM which aims at minimizing drastic decisions which can lead to a lack of comfort for end-users or to high prices paid for this 'forced' flexibility.

In the electricity chain, which goes from the production of electricity to its final consumption, a large number of actors, devices, and platforms are involved. Given its complexity, use cases are normally used by engineers to better structure and describe in a clear way the interactions (in a broad sense) which may occur between actors or devices in a specific context, once this is defined. In $[5,6]$ use cases are proposed which address DR in terms of load profile management via pricing mechanisms and via reliability based signals, respectively. In [7] a use case on load management through dynamic tariffs is presented, whereas in [8] DR is addressed through utility commanded load control. Additionally, in [9], the event of direct load control is examined. The importance of customer involvement (residential and commercial) is highlighted in [10], where the case of customers responding to DR signals from utility and implementing DR is shown. Automation functions on the customer side are also described in use cases; in [11] the provisioning of a DR Home Area Network (HAN) device is proposed, whereas in [12] the authors discuss how the pricing data and the DR event messages are passed to HAN devices, along with customer acceptance or rejection.

DR has also been the argument of several international projects realized in Europe. For instance, in the Scalable Energy Management Infrastructure for Aggregation of Households (SEMIAH) project, a system for DR services was implemented based on aggregation and scheduling of electricity loads in households. A front-end platform for smart grid services for households was developed, as well as a back-end system, which could manage aggregation, forecasting, and loads scheduling for at least 200,000 homes [13]. In the Peer-to-Peer Smart Test (P2P SmartTest) project, special focus is given to market issues and the market models/competition relations between different actors. It suggests how to define the baseline methodology, how to design demand response products, the measurement and validation activities, the bidding process for implementing demand response, and how to remove potential barriers in the system [14]. In our work, we do not focus on market aspects but we wish to show the advantages of a DSM program in terms of grid stability even using a small-scale lab-environment system, and we focus mostly on the technological aspects of such a work, with emphasis on obtaining and handling smart meter data efficiently. 
DR/DSM is a topic which attracts considerable scientific interest, with numerous articles in the literature addressing such issues. In [15] the distributed demand response (DDR) problem has been examined, where real-time balance in a neighbourhood has been studied. An algorithm is proposed for online DR control, whereas models are used for the network and customer loads. Simulations are performed for a large number of customers. In [16] a distributed mechanism for demand response aggregation has been proposed. The mechanism is used for charging purposes and uses the day-ahead allocation and the customers' real consumption. They use a household agent model and energy cost model. Communication aspects in DR have been examined in [17], where residential customers are encouraged to participate in a DR program, even without the employment of a smart meter. An internet based communication platform is implemented for this scope and they ensure data security.

In [18], the authors suggest a system for DSM, using the strategies of load shifting, flexible load shape, and peak clipping, among others. DSM is also the focus of [19], where an electric vehicle charging schedule is proposed. The usage of a microcontroller associated to wireless telecommunication technologies is examined for the implementation of DSM in [20]. The distribution system is divided into segments and the authors propose direct interaction between the customer and the energy provider instead of using a local energy management system. Market issues for DSM are examined in [21] with internal pricing being used for regulation service provisioning. Price responsive controllable loads are the topic of research in [22], highlighting the importance of customer involvement in DSM/DR programs.

As we can see, DR and DSM is a topic that entails many factors and different parts of the grid. The aforementioned articles examine a specific aspect of the system and analyse DR with respect to it, for example implementing DR in a neighbourhood and its potentials, demand response aggregation of multiple customers, telecommunication and data security aspects, or pricing and market issues. Despite the diversity of topics related to DR and DSM treated in the aforementioned works, none of them analyse nor implement an end-to-end system, that is, the full chain of actors from energy provider to final consumer. The aim of this work has been to create a small-scale system able to depict a real system in the most accurate way; through this system the effect of DSM is shown by introducing a smoother load curve in terms of peaks. Thus, the scope is to use and connect the necessary hardware and develop the required software so as to achieve this end-to-end system and make it operable for the purpose of the DSM experiment. For this purpose, a DR/DSM test bed has been designed and built from scratch in our Smart Grid Interoperability (SGI) Laboratory. The load consumption and in particular the active power per minute is measured via smart meters. In the test which is described in the following sections, a subset of fundamental actions has been covered:

- To monitor load consumption from the energy provider point of view;

- To decide on which hours would be peak hours, when the DR/DSM program could be applied;

- To improve the interaction: energy provider-multiple customers;

- To create a realistic IT communication network by using the Experimental Platform for ICT Contingencies (EPIC) [23] laboratory infrastructure for emulated networks;

- To shift or curtail loads either by means of an external actor action (DSM) or by the consumer response (DR);

- To monitor the new situation from an aggregated (load curve) perspective.

We decided to construct a DSM solution, which combines the testbed infrastructure creation and the software modules implementation and setup, in order to include more actors, thus providing a more complete developed test bed able to cover potential re-use for future test cases. It should be noted that the DSM solution implemented here mainly implies remote control of loads by an external actor. This can be one of the measures used as a DSM mechanism. Pricing incentives throughout the day can be also used for this purpose; however, such an approach is outside of the scope of this paper. The DR solution is similar to what we have implemented and it can be easily performed with the developed system, since the only difference lies in the actor that will control the load consumption (DSM: external 
actor-remote control, DR: consumer-manual control). The test itself consists of two phases: Phase A where monitoring and measuring of load consumption is performed in order to extract consumer profiles; Phase B where the actual DSM program is put in place.

The rest of the paper is organized as follows. Section 2 presents the materials and methods used in Phase A of the experiment: the test steps and the test bed are described here; the extraction and replication of load profiles is also explained. Section 3 shows the results observed in this phase: how the meter data is acquired and elaborated. In Section 4, the materials and methods for Phase B of the experiment are presented: how the interaction with consumer takes place; the concept of remote control is explained. Section 5 presents the results observed in this case. Section 6 discusses several issues emerged during the running of the experiment and concludes this work.

\section{Materials and Methods for Phase A of the Experiment}

\subsection{Description of Test}

\subsubsection{Test Steps}

For the realization of the test, a first step consists of the monitoring of end-users consumption. For this purpose, real residential profiles were examined and replicated in the lab. Three different daily consumption profiles were replicated (through various appliances) and then measured through smart meters. The metering data were forwarded by the smart meter to the data concentrator and thereafter to Actor B, which represents the energy provider in our test. In the next step, the data were sent to Actor A, where aggregated and separate consumption profiles were created for these end-users.

Conclusions were driven with respect to the consumption as a whole; peak hours of consumption were identified and decisions for proceeding with a DSM program were taken. According to this program, Actor A takes control of certain devices within the home; the consumption of those devices (loads) is shifted to a time slot where overall consumption is not at its peak. For this purpose, messages are sent to end-users by Actor A to ask for participation in a DSM action for a given period. After positive feedback from the end-user is received, certain electrical devices, like the washing machine or the air cooling/heating device can be controlled by Actor A. It is worth mentioning that this assumes the existence of an agreement/contract between Actor A and each user involved in the DSM. The new consumption situation is hence monitored through the smart meters and conclusions are driven. Figure 1 shows the message sequence chart describing the above steps, where NNAP stands for Neighborhood Network Access Point, which is represented by the data concentrator, located in the Medium Voltage/Low Voltage (MV/LV) substation.

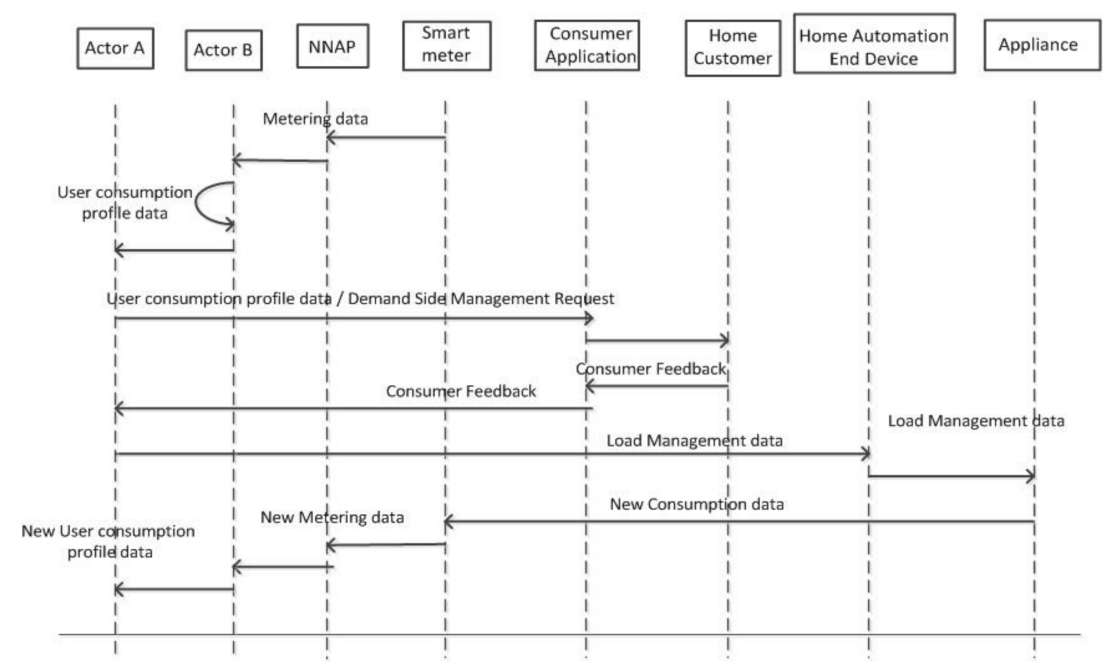

Figure 1. Message sequence chart. 


\subsubsection{Test Bed}

This section presents briefly the hardware and software components that constitute the Test Bed used for the needs of Interoperability (IOP) testing activities taking place at the Smart Grid and Interoperability (SGI) Lab. The Smart Metering rack consists of 2 data concentrators, 18 smart meters, 3 computers, 1 programmable load, 16 single phase $(1 \Phi)$ plugs, 2 three-phase plugs $(3 \Phi)$, electric loads of different power levels $(\mathrm{kW})$, and 2 programmable plugs. It has to be stated that some of the components presented before are accompanied by respective software packages used for simulating the activities of relevant entities (e.g., Aggregator, Energy Service Company (ESCO), DSO, etc.).

The Smart Metering rack contains two data concentrators, each of which controls 8 single phase and one three-phase smart meter. The group of smart meters controlled by each data concentrator represents one subsystem. The two subsystems are supposed to represent two different neighbourhoods of residential consumption points, where respective smart meters are connected. Both data concentrators are supplied by a single phase $(1 \Phi) 230 \mathrm{~V}_{\mathrm{AC}}$ power supply. They are accompanied with specialized software that allows an operator (energy provider side) to configure their functioning. Additionally, through this software, the operator gains the capacity to interact with the registered smart meter and to change the parameters as needed.

Two computers are used for Actor A (e.g., Aggregator, energy provider, ESCO interacting with home automation network through the energy management communication channel, [2]) and Actor B (metering company, DSO interacting with home automation network through the metering communication channel, [2]) to have access to the data. The third computer is assumed to be at the customer's premises and acts as the interface between customer and energy provider: signals are received from the DSO inviting the end-user to participate in the DSM program and the client's response is communicated.

In order to apply realistic load curves to the smart meters in the rack, electric loads of different power levels (kWs) have been turned on and off for different time frames. Additionally the programmable load device has been used to exactly replicate a specific load profile into one of the smart meters available in the rack. Programmable plugs have been used to provide the possibility of load shifting. Once Actor A receives the green light for the DR/DSM action to be performed, they are granted the capacity to control the programmable plugs for smoothing the load profile of the consumer based on the actual needs of the system. A Data Acquisition and Control Platform has been used for transforming two typical electric sockets into programmable ones.

Some limitations related to the maximum instantaneous power exist in the rack due to the cabling used by the provider to connect the smart meters. For the single phase smart meters of nominal voltage 230 VAC L-N the maximum instantaneous demanded power is $3 \mathrm{~kW}$, whereas for the three-phase smart meters of nominal voltage $400 \mathrm{VAC}$ L-L it is equal to $20 \mathrm{~kW}$. Additionally another constraint needs to be mentioned: the sum of connected loads overall cannot be higher than $20 \mathrm{~kW}$.

\subsection{Load Profiles-Extraction and Replication}

\subsubsection{Extracting the Residential Consumption Profiles}

The first step of the DSM test realisation is to create and measure the residential consumption profiles. We considered three homes to analyse and measure their electrical consumption. The consumption profiles used have been extracted by the Centre for Renewable Energy Systems Technology (CREST) demand model created by the University of Loughborough [24]. The model can create consumption profiles that vary every minute and which correspond to typical profiles of consumers in the UK. It also takes into account several parameters, such as the number of people in each home (from 1 to 5 people), the month of the experiment, the day of the week (weekday or weekend), and the electrical devices that are present in each home. The model simulates the possible occupancy of the house throughout the day and creates a curve of the number of active tenants 
throughout the day. It simulates the possibility that a specific electrical device is switched on/off every minute within a day and creates a curve with the resultant electrical consumption.

We assumed that the consumption takes place during a weekday in July. We chose a summer month in order to show the effect of a cooling device, which is a high energy consuming apparatus, as will be shown in later sections. We considered four people in Home 1 and Home 2, and two people in Home 3. It is considered that all houses are equipped with common electrical devices (television, fridge, freezer, kettle, oven, washing machine, microwave, iron, vacuum cleaner, among others).

The model simulates the probability that a person will be actively involved in the usage of electrical devices during a day and gives a respective curve related also to the house occupancy. It also simulates the probability that one of these devices will be switched on or off every minute and gives the overall consumption curve. For the three homes, the equivalent curves are shown in the following (Figures 2-7). In Figures 2-4 the external radiation can also be observed, which depends on the time of the year and the location that the consumption is supposed to take place; in this case it is in the UK during July.

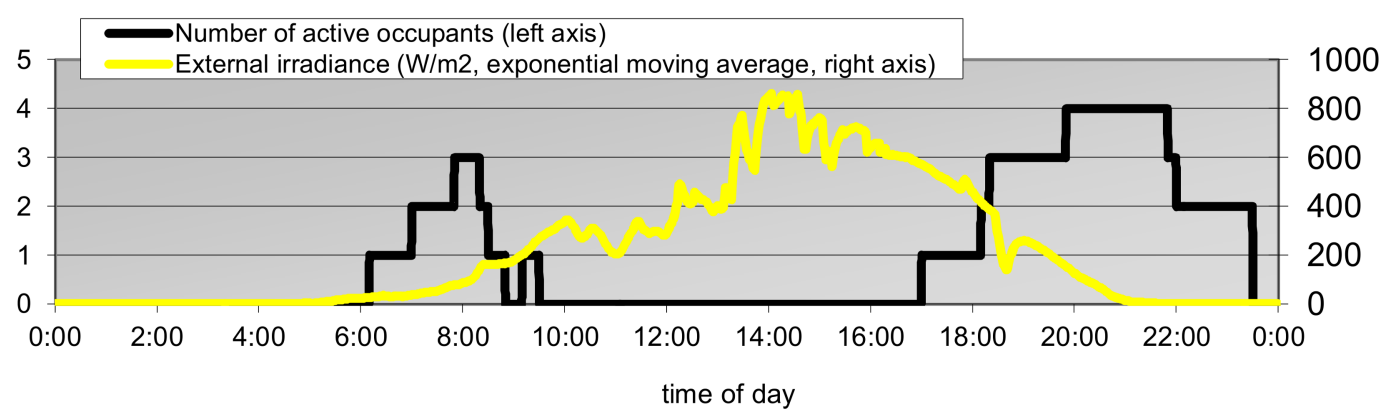

Figure 2. Number of active occupants-Home 1.

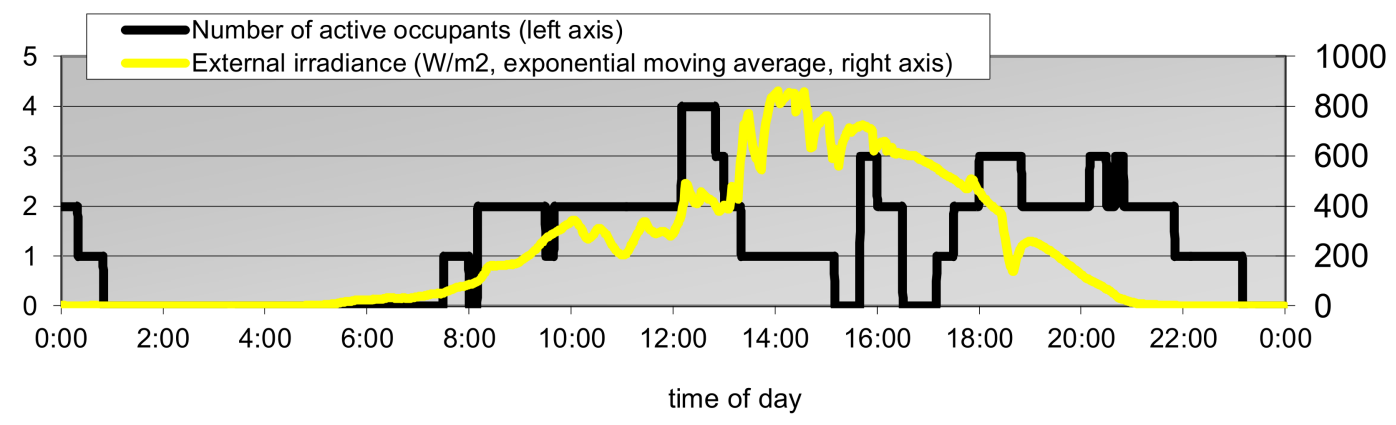

Figure 3. Number of active occupants-Home 2.

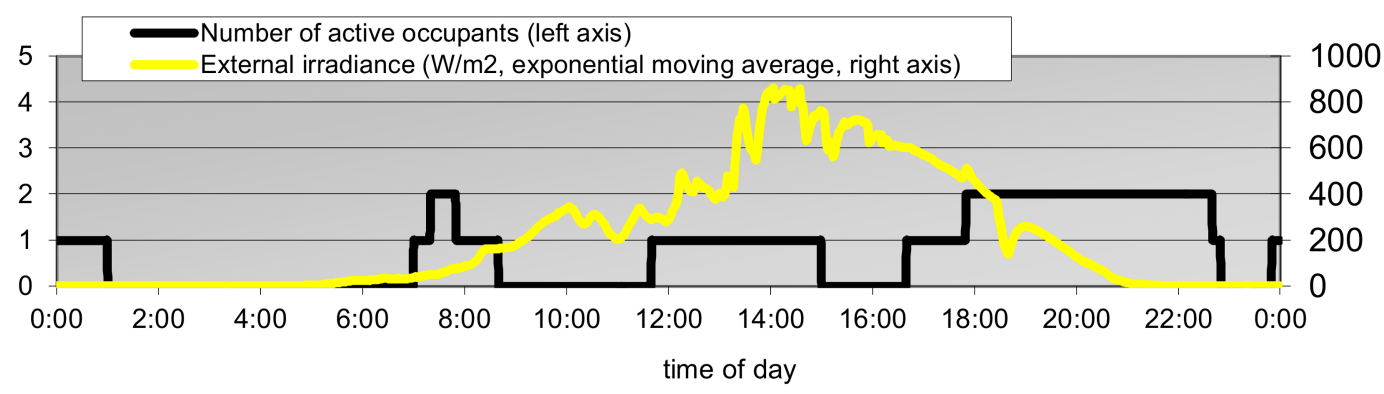

Figure 4. Number of active occupants-Home 3. 


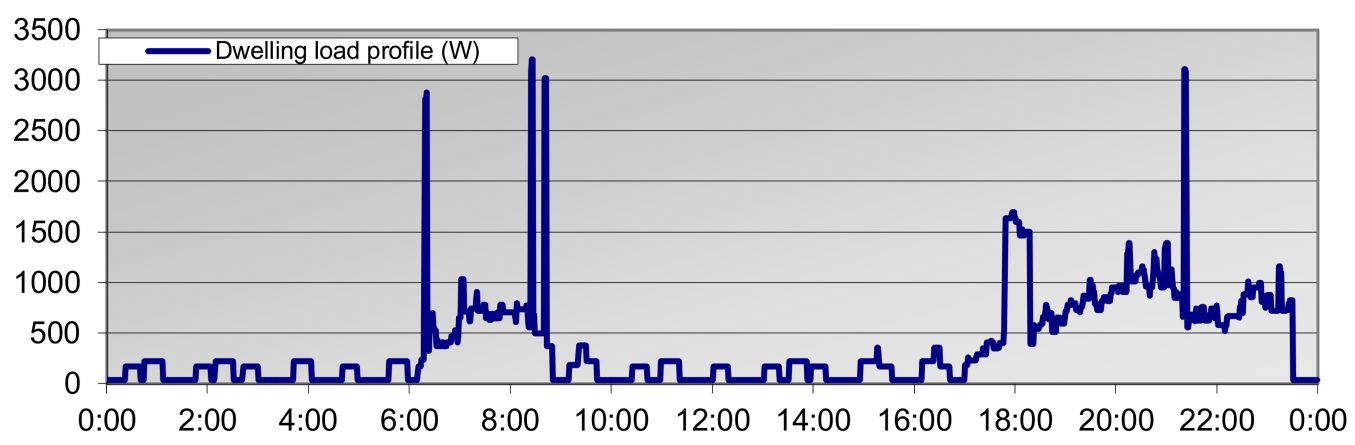

Figure 5. Consumption profile--Home 1.

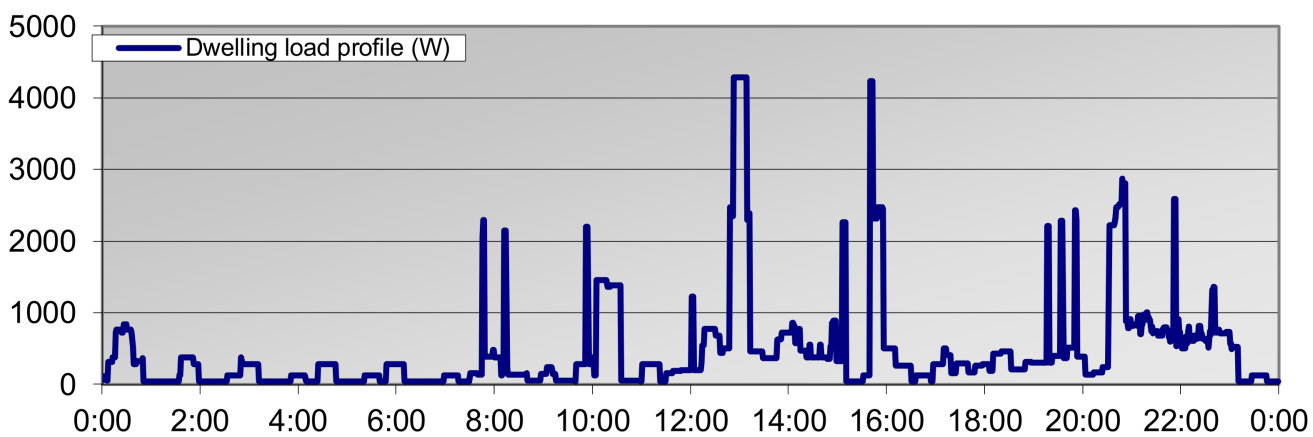

Figure 6. Consumption profile-Home 2.

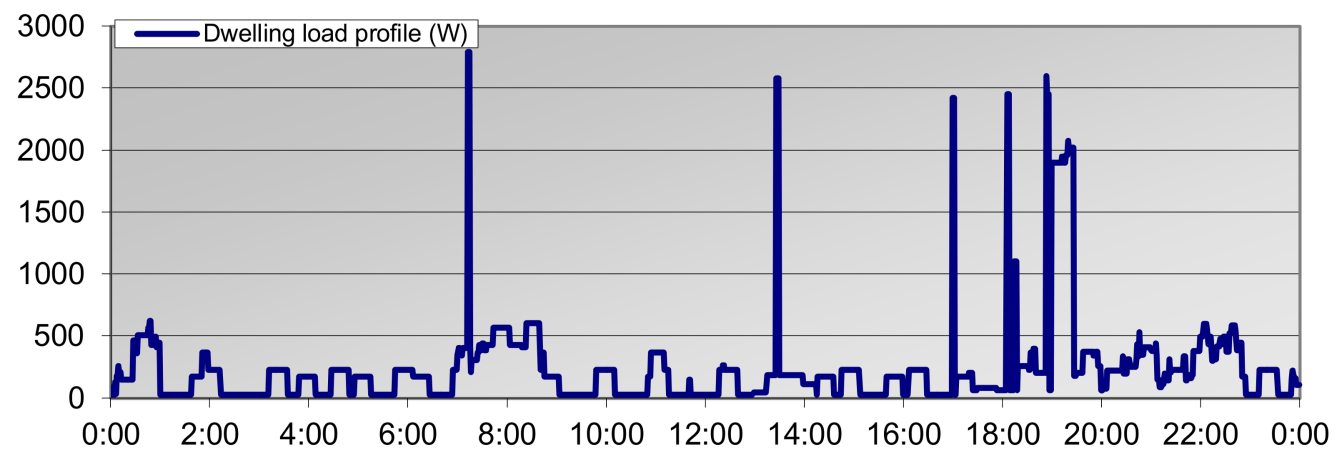

Figure 7. Consumption profile--Home 3.

As it can be seen from Figures 2-7, we have considered different occupancy profiles for the three homes. For example tenants from Home 1 are mainly away during the day and there is much activity during the evening. Home 2 presents a different situation, where the house is occupied by at least one person throughout the whole day. Finally, Home 3 presents a situation where its tenants are mostly active during the morning and evening and are partly present during the rest of the day. The electrical devices considered in each house do not differ a lot, thus highlighting the differences created by different occupancy profiles. It is noticed that we obtain three different consumption profiles that present peaks especially in the morning and the evening, mainly because people are at home during these hours on a weekday. In addition, lighting at night increases the overall consumption when external irradiance falls. 


\subsubsection{Replicating Profiles in the Lab}

The model used to calculate the consumption profiles unfortunately does not take into account electrical devices for air cooling/heating purposes. The reason may be because it has been based on dwellings in the UK, where heating is mainly based on other sources (gas, oil, etc.) and cooling is not that crucial due to the mild summer. However, in other geographical locations the situation could be rather different. In order to make our analysis more generic we have included this parameter: the usage of air cooling/heating devices in homes. We assumed that the three homes are equipped with such an electrical device which is used based on the house occupancy. Table 1 defines the exact usage of the air cooling/heating device that has been assumed for all three homes.

Table 1. Usage of air cooling/heating device in all homes.

\begin{tabular}{cccc}
\hline Time & Home 1 & Home 2 & Home 3 \\
\hline \multirow{2}{*}{ Morning } & $08: 00-09: 00$ & $09: 00-09: 48$ & $08: 00-08: 30$ \\
& & $10: 30-12: 50$ & \\
\multirow{2}{*}{ Afternoon } & & $13: 00-14: 05$ & \\
& & $14: 10-15: 00$ & $12: 00-14: 45$ \\
\hline \multirow{2}{*}{ Evening } & $17: 00-20: 00$ & $17: 40-16: 20$ & \\
\hline
\end{tabular}

In the lab, we replicated the active power only and we did not consider the reactive power of the consumption profiles in order to facilitate the test situation. Without alteration of the scientific findings, we used three of our smart meters to create one home profile. This has mainly been done because, as mentioned, the maximum power that our smart meters can reach is $3 \mathrm{~kW}$. Although this limit is realistic for some countries (i.e., Italy-for flats), this is not the case for others. For example, the limit in Germany is $4.6 \mathrm{~kW}$; France has a limit of 6 and $9 \mathrm{~kW}$ (depending on the house); the UK, Greece, and Finland have a limit of 5.75, 8, and $5.75 \mathrm{~kW}$ respectively [25]. This way, we manage to increase the consumption limit of each house, and we test the operation of more smart meters and their interaction with the respective data concentrator.

In this manner we can achieve higher power values that can depict the situation in many countries. Without loss of generality, we assumed that one smart meter stands for the consumption realised by kitchen electrical devices, one for the rest of the house, and the third for the air cooling/heating devices. We also assumed that the consumption needs with respect to the rest of the electrical devices (washing machine, cooking devices, TV, etc.) are similar for other countries/locations if compared with the UK. In our experiments, it is considered that the three houses are located in Europe without further location constraints.

We have used smart meters no. 4, 5, and 6 to replicate Home 1; smart meters no. 13, 14, and 15 to replicate Home 2; smart meters no. 7, 8, and 9 for Home 3. Figure 8 shows the smart meter rack and the smart meters used to replicate the houses' consumption. Different smart meters and the two data concentrators have been used to show that the system works as expected, and the devices are interoperable with each other. Home 1 and Home 2 consumption profiles have been replicated manually with the usage of common electrical devices: hair dryers, photovoltaic lamps, fridge, vacuum cleaner, microwave, coffee machine, kettle, and normal lamps. For replicating the consumption of an air cooling/heating device, two portable heaters have been used for Home 1 and Home 2. It has also been verified that the consumption of these heaters was similar to the consumption of an air conditioner that has a medium sized window unit $(\sim 900 \mathrm{~W})$. The tests to replicate the consumption of Home 1 and Home 2 lasted three days in order to fit $24 \mathrm{~h}$ of the day in which monitoring of consumption profiles takes place into working hours. 
Home 3 consumption has been replicated automatically through the use of the programmable load. Similarly to Home 1 and Home 2, the consumption has been divided into 3 smart meters. We have examined in depth the consumption profile created by the model in order to extract the consumption for the first two smart meters. For the air cooling/heating device, we have assumed that it has been used as indicated by Table 1 . The experiment ran for three days, one for each smart meter.

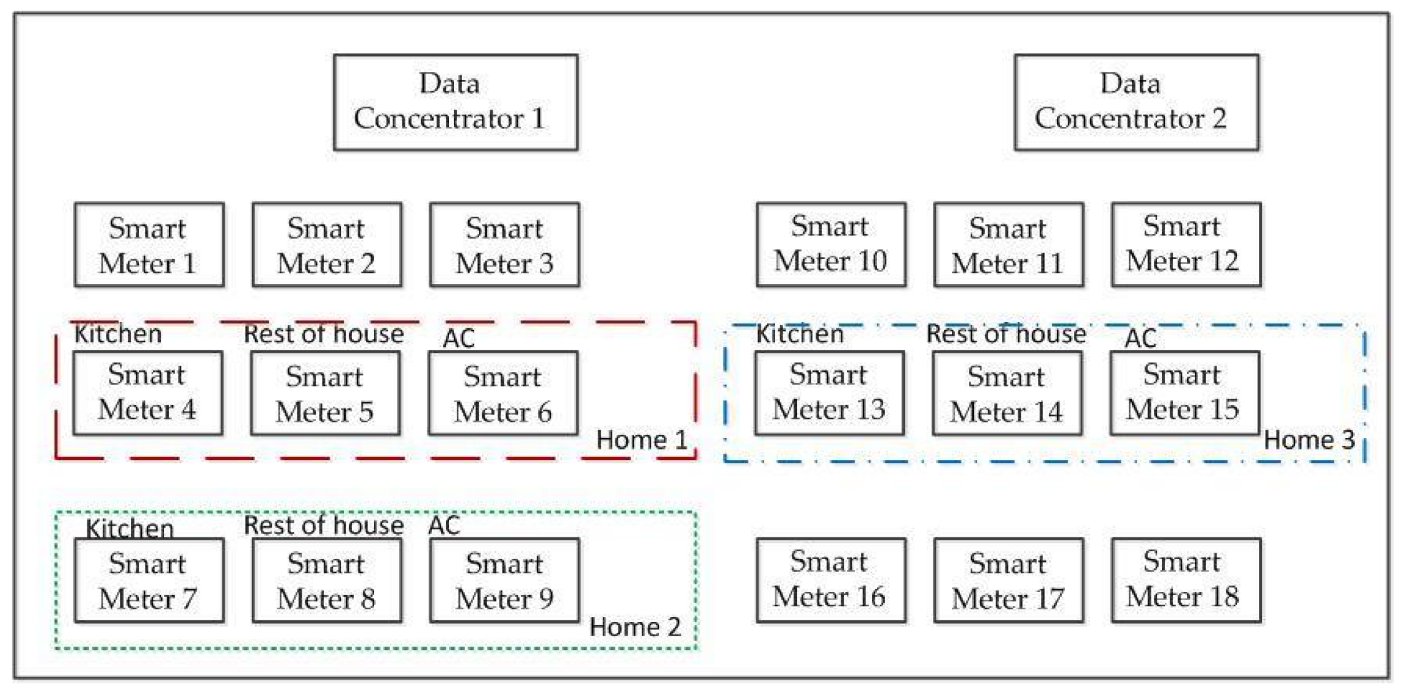

Figure 8. Smart meters used for the houses' consumption replication.

\subsubsection{Programmable Load}

The programmable load has been used to replicate the Home 3 consumption profile. It can produce a load that varies with a frequency of one minute. The maximum load output corresponds to $3 \mathrm{~kW}$ and it can be programmed to run for a specific time period. It can produce a load that is resistive, inductive, and capacitive or a combination of the above. We have created a graphical interface in LabView that enables us to give the desired input to the instrument so as to run a profile of a given duration $(24 \mathrm{~h}$ ). The device has been connected to one smart meter each day (total three days). Figure 9 shows a snapshot of the interface created to program the instrument. It can be seen that there are 5 columns of interest showing how the program works, which are explained as follows:

- $\quad$ The 'mode' column defines the variable output provided by the programmable load. Mode 2 stands for a programmed output in terms of power. We can also have a programmed output in terms of current (mode 1 ), voltage (mode 0 ), and resistance (mode 3 ).

- The 'setpoint' column stands for the value of power we wish to obtain at the output.

- The 'crest factor' defines the ratio $\mathrm{V}_{\max } / \mathrm{V}_{\text {rms }}$ (maximum voltage/rms voltage). We set this parameter to 1.414, which means that the voltage would follow a normal sinusoidal curve.

- The 'power factor' stands for $\mathrm{P}_{\mathrm{F}}=\cos \varphi$, meaning the ratio of the real power flowing to the load to the apparent power. In our experiments we set this value to 1 , meaning that only active power is present, thus the load is resistive.

- The 'duration' specifies the duration of the specific output value in seconds.

As shown in Figure 9, the graph on the upper right shows the profile that has been inserted for execution, whereas the graph on the bottom right stands for the profile that has been executed so far. These graphs can also be exported by the program for further usage. 


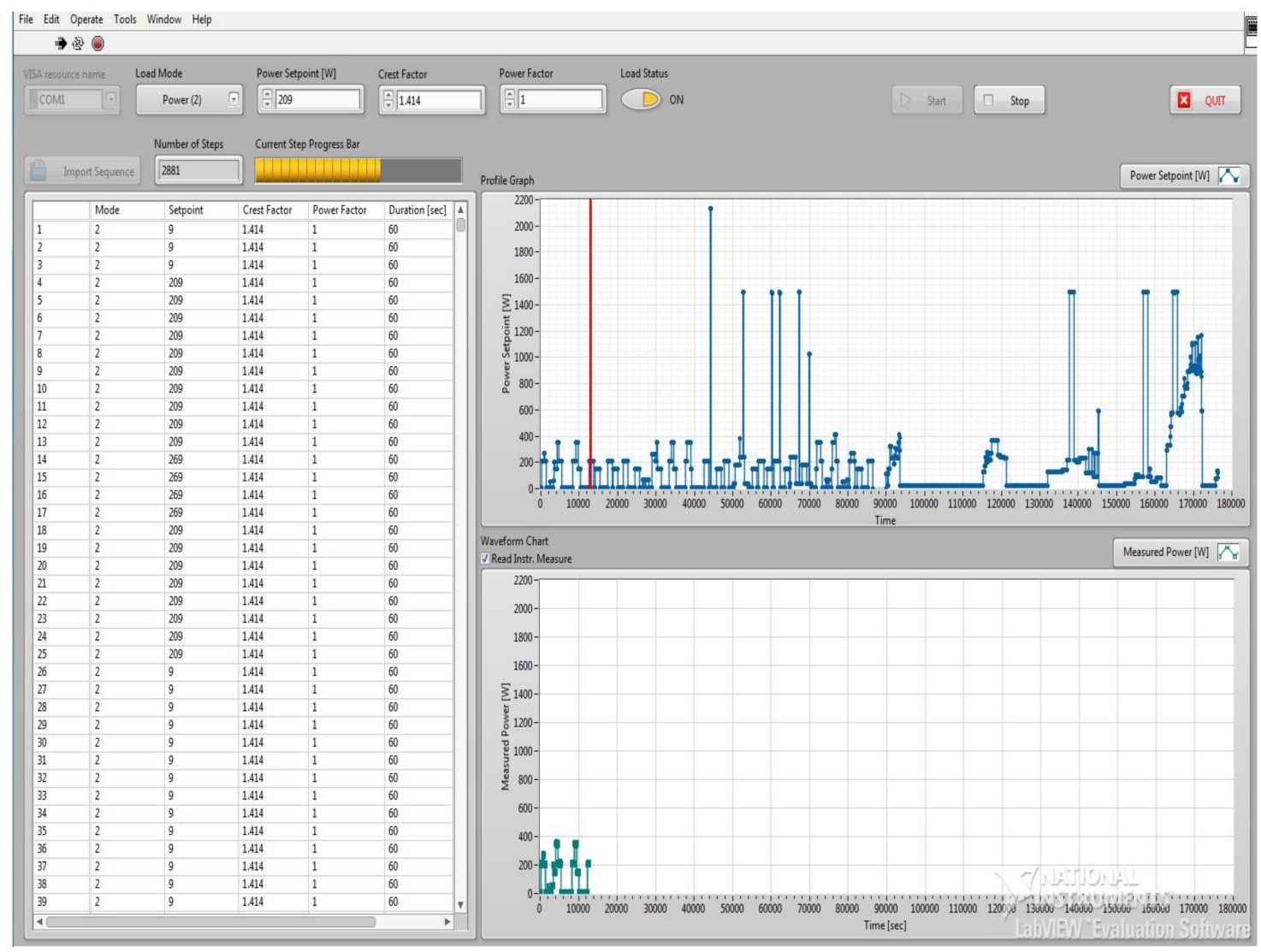

Figure 9. Snapshot of the programmable load.

\section{Results for Phase A of the Experiment}

\subsection{Meter Data Acquisition}

As previously mentioned, the objective of Phase A is to monitor the residential profiles at the energy provider side and create the graphs of the daily consumption-separate and aggregated. For this purpose, the electrical values per minute are required. At the energy provider side, it is possible to monitor the smart meters and their loads through the data concentrators. The software also enables us to change critical smart meter parameters and to program the data concentrator so as to obtain the necessary electrical values.

The two data concentrators can monitor and control the smart meters; both concentrators are able to monitor all the smart meters or part of them according to how their parameters are set. In this experiment, we have determined that the left hand side smart meters (no. 1-9) are monitored by the left concentrator, whereas the right hand side smart meters (no. 10-18) are monitored by the other concentrator. Both data concentrators allow us to check the instantaneous values measured by the smart meters. Among others, we can monitor the instantaneous voltage, current, active and reactive power. The data concentrators enable us to obtain reports with respect to the consumption of the smart meters. Several values can be depicted, like the imported and exported active power as well as the reactive power in the four quadrates. In general, there are a lot of options in terms of monitoring and controlling the equivalent smart meters. In this work, we only refer to the most important ones for this experiment.

Programming with the Object Identification System (OBIS) Structure

Both data concentrators have the option to be programmed so as to extract the desired electrical values from predefined smart meters. This can be done by means of xml scripts. The program should 
have a specific structure. The task and its characteristics are defined, like the name of the cycle and the priority of the task. The period of the task or alternatively the start and end moment should also be defined. In addition, the smart meters on which the cycle will be executed are defined.

The possible actions are: <get $>$, <set $>$, and <action>. In this case, we are interested in the <get $>$ option, since we wish to obtain specific electrical values. For this scope, OBIS codes are necessary, which define such an electrical value. The OBIS codes consist of 6 parts separated by any of the characters ":--". In addition, the OBIS class and element are necessary. All this information regarding the OBIS structure is included in [26]. The OBIS is actually what the standard IEC 62056 (DLMS-COSEM) uses. Since we are interested in obtaining electricity values, we used the specification for the six groups of the OBIS code A, B, C, D, E, F related to electricity. The general definition for these groups can be found in [26].

In our experiments, we took:

- $\quad \mathrm{A}=1$, which stands for electricity values.

- $\quad \mathrm{B}=1$, which means that no channel is specified.

- $\quad$ C stands for the value we wish to measure; in our case we used several values mainly with respect to the active and reactive power. Specifically, we used values 1, 2, 3, 4 that refer (independently from the phase) to the imported active power (1), the exported active power (2), the imported reactive power (3), the exported reactive power (4); values 21, 22, 23, 24 that refer to the same values but specifically for phase 1 ; values $5,6,7,8$ that refer to the reactive power in the 4 quadrates; value 31 for current; value 32 for voltage; value 13 for the power factor.

- We extracted many of these values, so as to have an exhaustive list of values for usage.

- For group D we used values 7 and 8 that stand for instantaneous values and values computed in the entire time integral of interest. In this case we are mostly interested in the instantaneous values, since the extraction of values takes place each minute.

- Group E for electricity can define the different tariffs, harmonics, phase angles, and transformer line quantities. Since we are not interested in getting any particular value for the above quantities, we set $\mathrm{E}=0$ indicating the total/fundamental value.

- $\quad \mathrm{F}=255$, which refers to the time stamp of the most recent billing period; other values would refer to a time stamp of historical billing periods.

We have defined the class to be 3, which stands for registering values. With respect to the element, this refers to the so-called attributes of each class. We have defined the element to be 2, which stands for the actual value of the desired quantity. Other attributes could be the 'logical name' of the quantity and the 'scaler unit'.

\subsection{Meter Data Elaboration}

The energy provider that monitors the metering channel is called Actor B, as showed in Section 2.1.2. Generally the expected amount of data is considerable, since an almost real-time recreation of the profiles is aimed at (data acquired every minute). For the duration of one day, we expect to have 1440 values for each smart meter, but it is clear that for longer considered periods this size increases considerably. For the profiles replication, we have used the instantaneous values of the active power. It is worth mentioning that due to the fact that the concentrator 'asks' the current value to each smart meter in a sequential manner, some delays are accumulated in the metering process and it is not possible to get a value (or collection of values) for each smart meter exactly at each time step (one minute). At this stage the large amount of collected data needed to be filtered, processed, and re-organised. This step is done by our software module implementation (Python language script) which groups and selects the relevant data into a single excel worksheet for each house. As made clear in the previous section, three different smart meters are used for each home to take into account the fact that in certain Member States residential customers have higher $(>3.3 \mathrm{~kW})$ contracted power availability. From a technical point of view this introduces a shift (due to the sequential reading of 
the smart meters piloted from the concentrator) between the three smart meters which needs to be managed. This is tackled through another software module implementation of ours (Matlab script). In Figure 10, the daily graphs built from the read value for the three homes are reported.
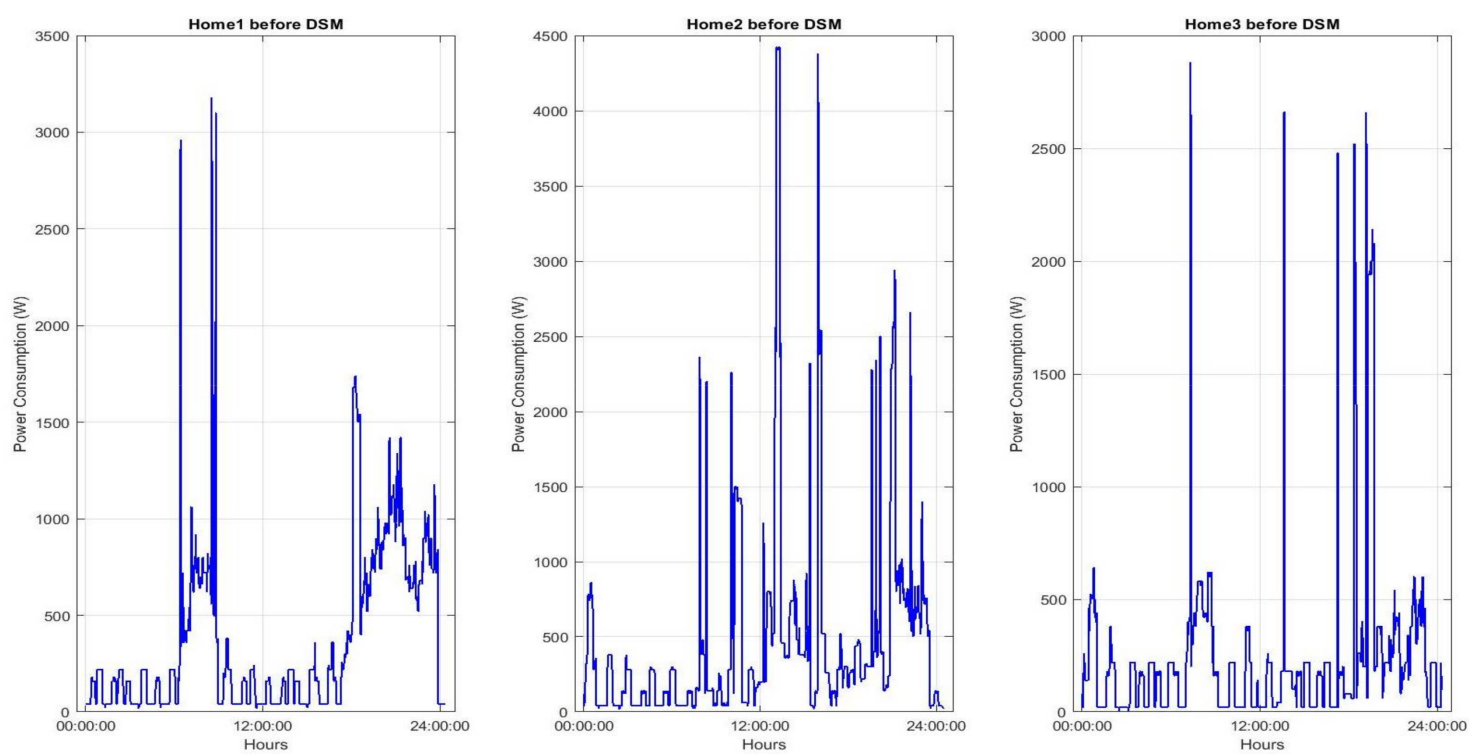

Figure 10. Snapshot of the three measured profiles.

It is notable that the measured profiles match with the initial profiles generated from the CREST model. As mentioned, due to the fact that no air-conditioning/heat-pump was available in the version of the CREST model used, we have added it to the three profiles by connecting a real heating system to the smart meter belonging to each of the considered homes. The previous profiles, as expected, are thus modified, as can be noted from Figure 11.
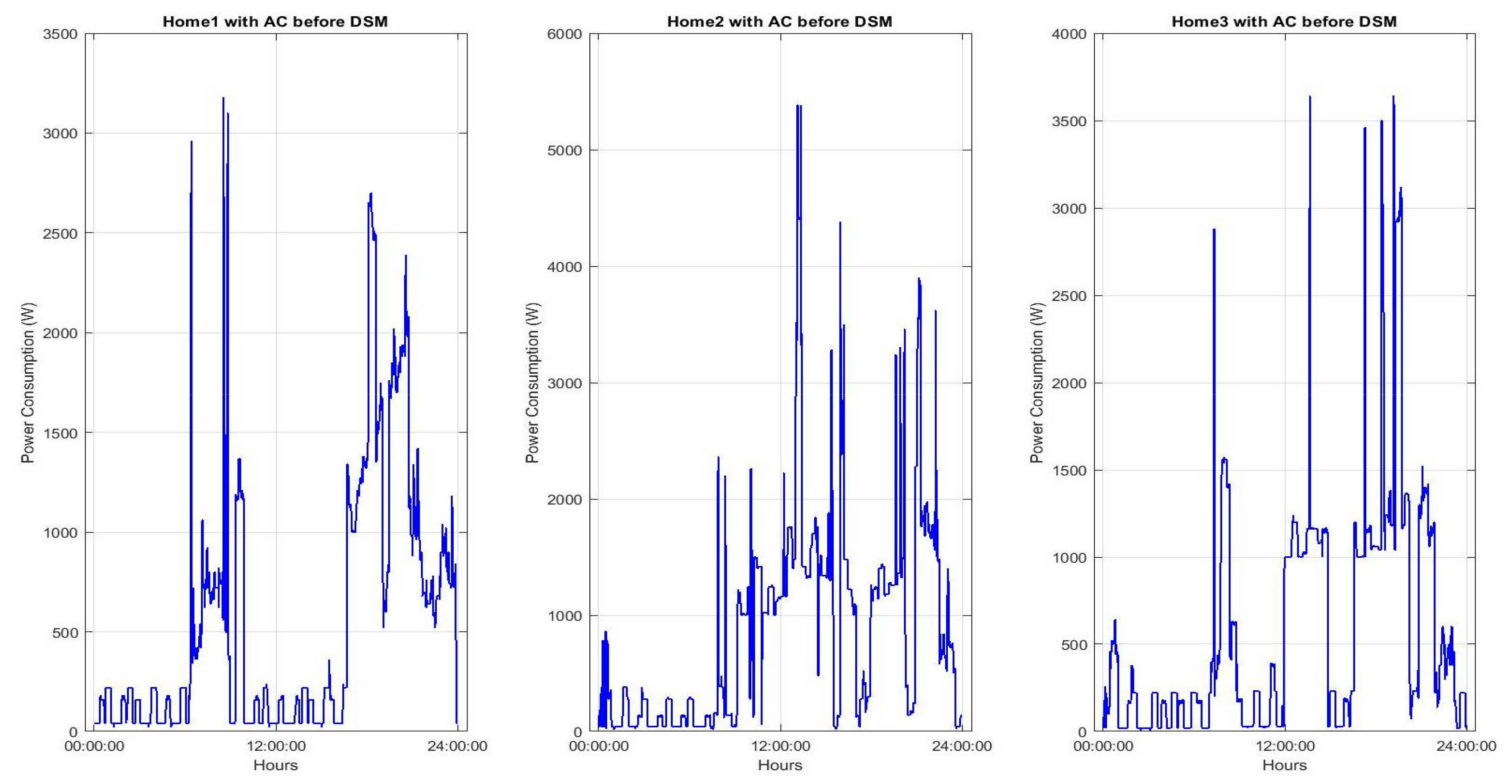

Figure 11. Snapshot of the three measured profiles with the air conditioning.

By summing the three measured profiles together an 'aggregated' curve can be calculated. This is mainly done to identify the existence of a peak time period, which is comprised between 18:00 and 20:00. Figure 12 below shows the aggregated curve obtained by the measured data. 


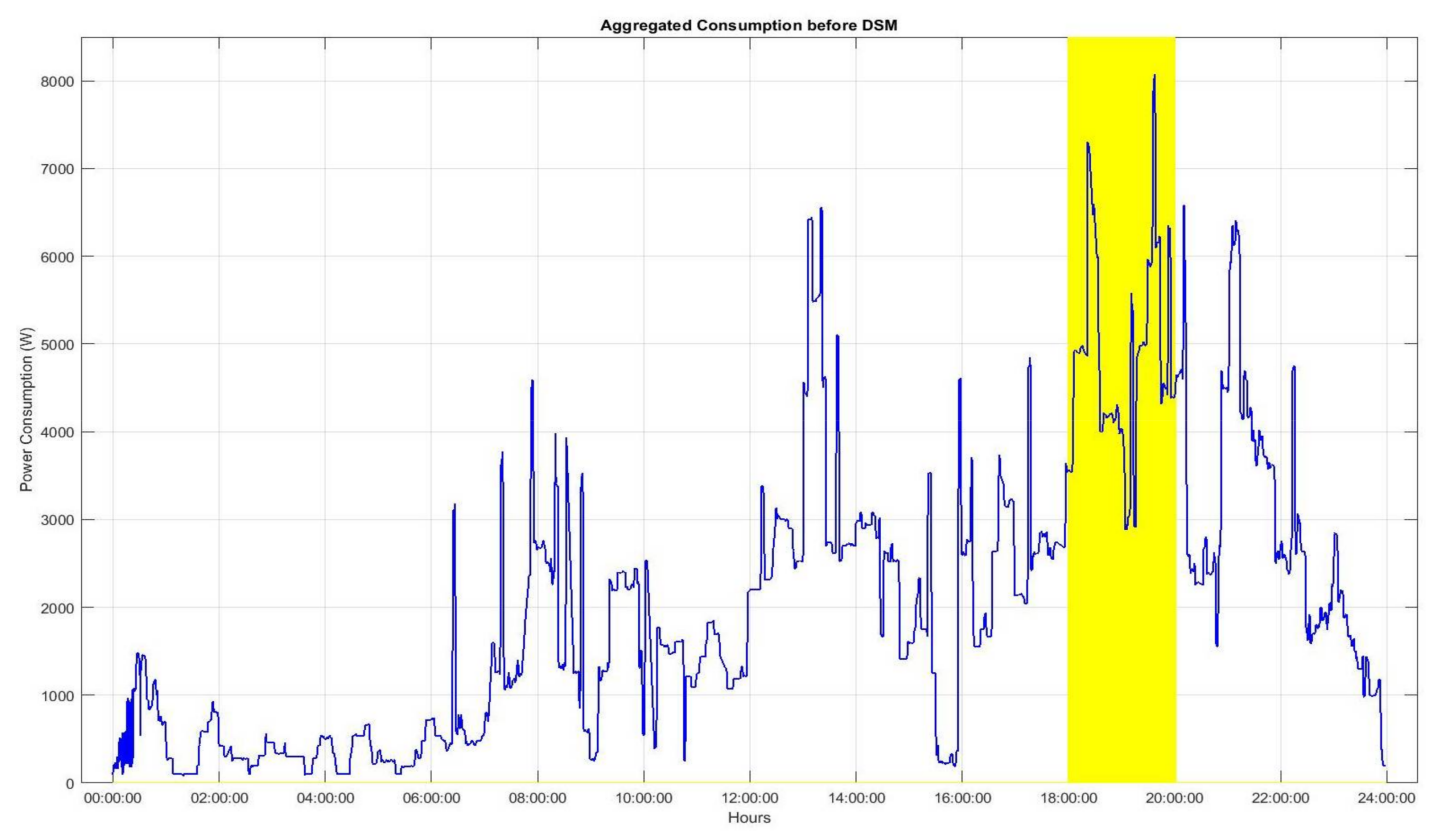

Figure 12. Aggregated curve of the three measured profiles (with the addition of the air conditioning).

It is easy to notice the existence of two main peaks in the region of interest which are slightly above $7 \mathrm{~kW}$ and $8 \mathrm{~kW}$, respectively. Therefore, it is decided that the DSM program takes place between 18:00 and 20:00.

\section{Materials and Methods for Phase B of the Experiment}

\subsection{Interaction with Consumer}

The interaction between the main entities of the DM system are presented in this section. The possible automated interaction between the smart home appliances and the smart meter is outside of the scope of this research work. Figure 13 illustrates those roles and the communication between them.

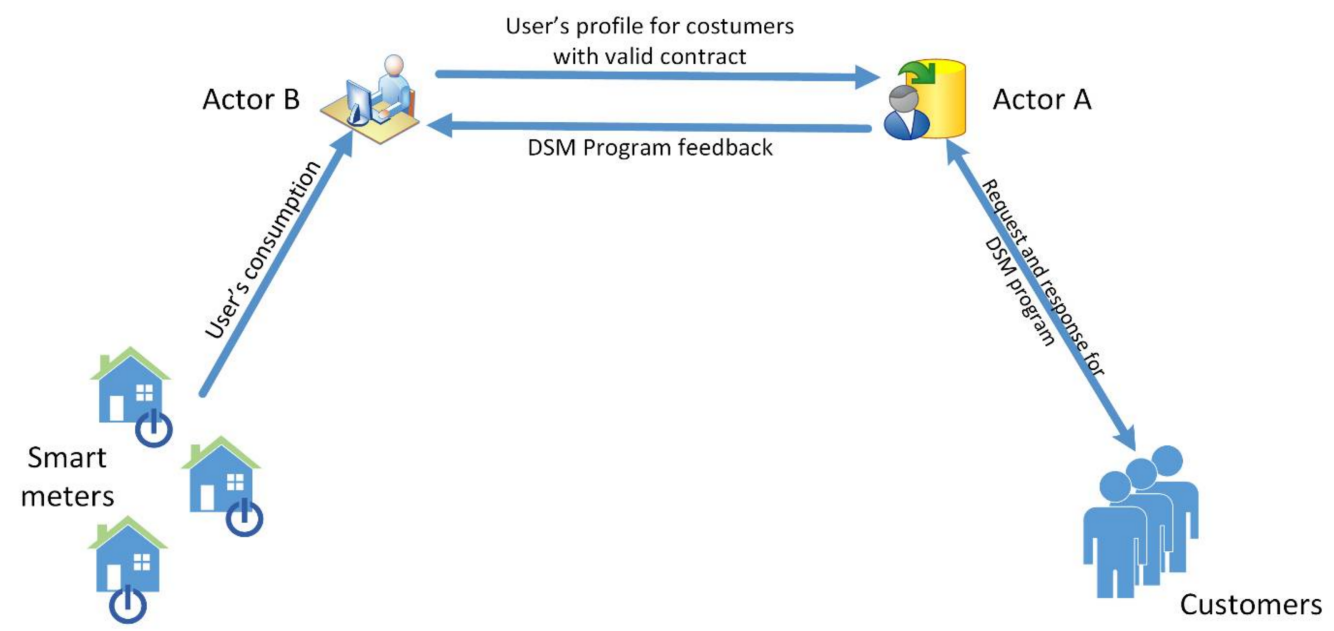

Figure 13. Data Management actors of the demand side management (DSM) system.

The main involved entities and the communication process used to implement the demand side management system is described in the following: 
1. Actor $\mathrm{B}$, is responsible for controlling the metering channel, and thus for collecting the consumption data from each smart meter. The actor analyses the data and creates a consumption profile for each smart meter. The profiles created for customers that have a contract with both Actor B and Actor A are inserted into the software application (Figure 14) and are available for the next steps.

2. Actor A controls the energy channel; the principal role is to introduce the proposed energy efficiency method to the system. The main task is to interact with the client and adjust various aspects of energy consumption. In our example, the actor is able to access the same amount of information as Actor B, for the customers that have a contract both with Actor A and Actor B (Figure 14). Based on this input, he/she is able to request that the customers participate in the desired DSM program. The terms and conditions of the DSM are explained in the contract. In Figure 15 we are able to observe the question proposed to the customer in order to participate in the proposed DSM program. Afterwards the actor is able to collect all the necessary customers' responses (Figure 16) and implement/optimize the DSM program.

3. Customers are able to check their energy consumption. They can access their personal consumption profile and they are urged to participate to the proposed DSM program (Figure 15). Their responses are collected by Actor A.

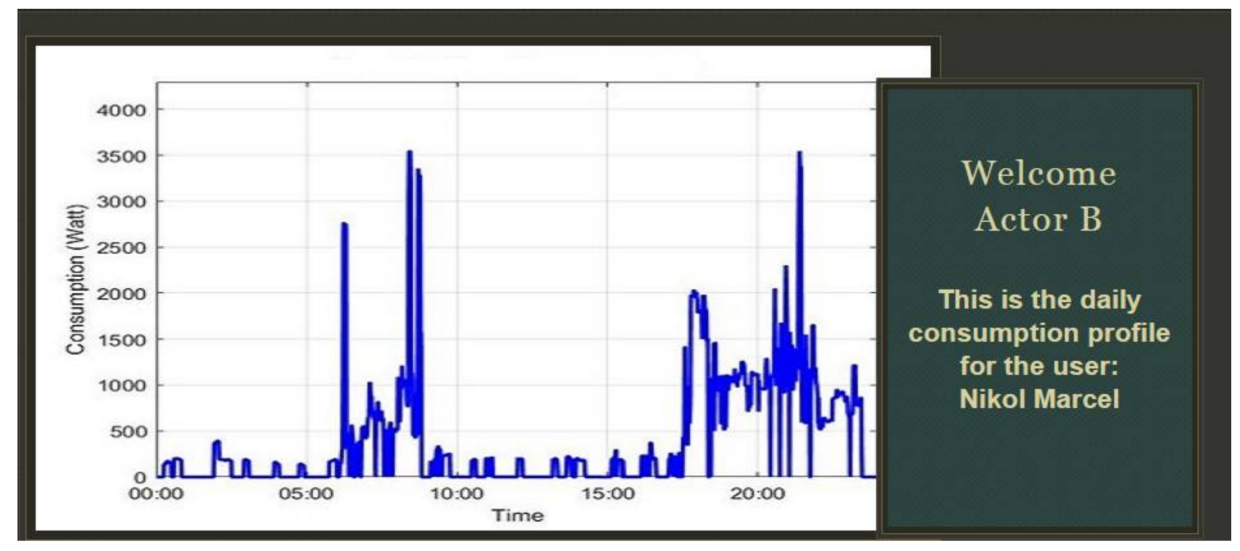

Figure 14. Actor's B application interface-shows customers'/smart meters' daily consumption profiles.

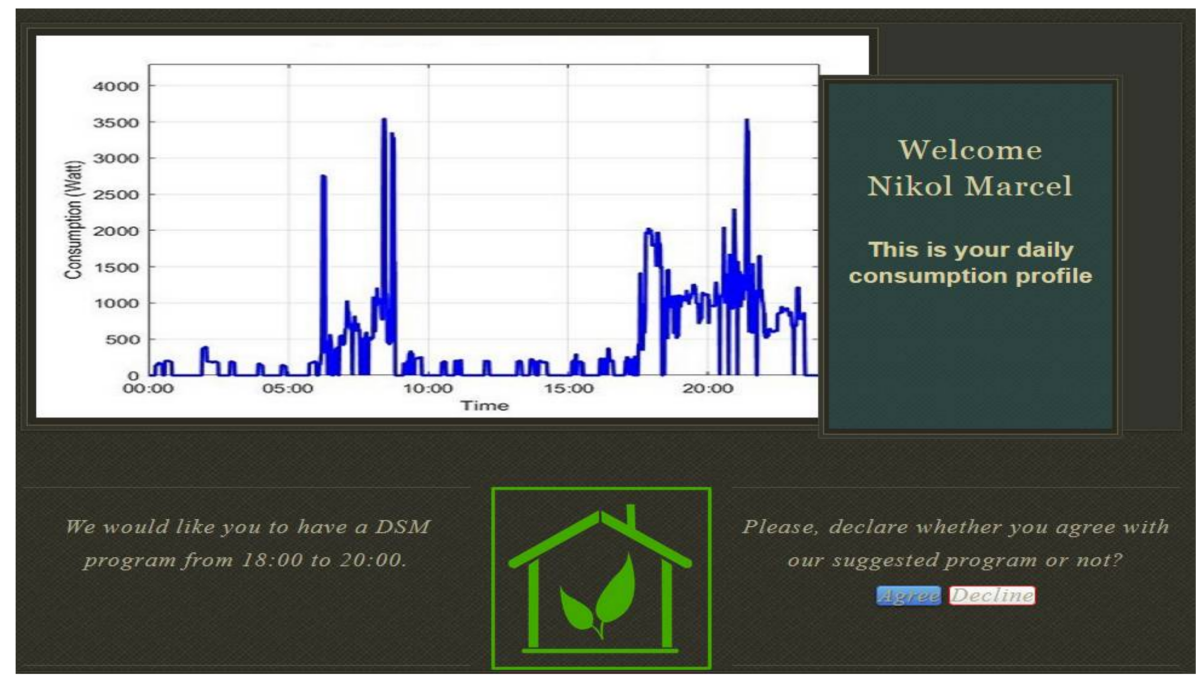

Figure 15. Customer's application interface-shows Actor A's request to the customers in order to participate in the DSM program. 


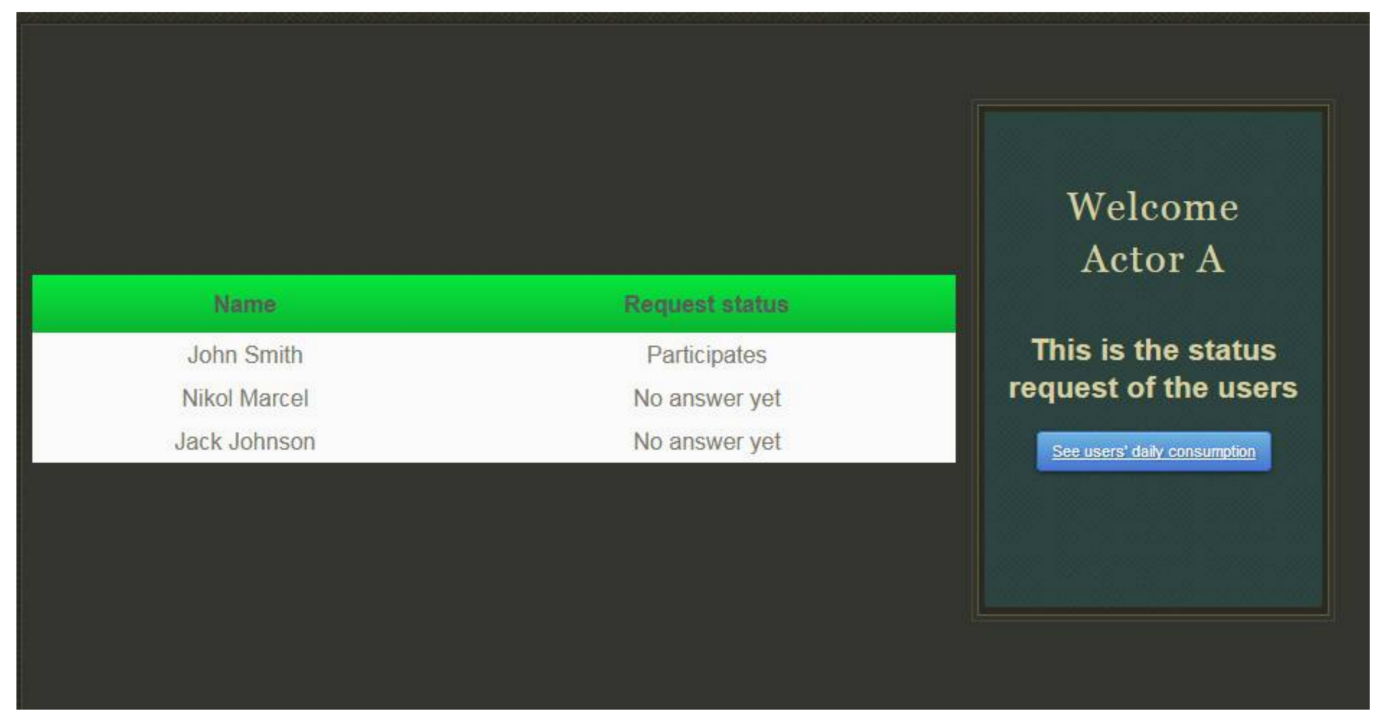

Figure 16. Actor's A application interface-shows the summary of the customers' responses for their participation in DSM.

In our experiment, it is supposed that all three customers finally agree to participate in the DSM program. The load control by Actor A is presented in Section 4.2.

Implementation Architecture and Software

The ICT architecture and the backbone implementation components are presented in this section (Figure 17). The main ICT software elements used for this implementation are:

- The File Transfer Protocol (FTP) server, which is the data storage where smart meters' data reports are recorded. This procedure is accomplished by the data concentrator which is able to extract the measurements from the smart meters. Afterwards, Actor B is able to access these reports and to create the consumers' consumption profiles. In our example, it is considered that the server is at the premises of Actor B.

- The Database server is where all the processed data is stored. Firstly, Actor B is responsible to place the user's profiles in the database. Only the profiles corresponding to customers that have a contract both with Actor A and Actor B are placed in this database. Secondly, Actor A takes those profiles and based on the DSM program, places the requests to the appropriate users by updating the suitable database fields. Thirdly, the consumers are informed about the request and they respond whether they want to participate in the program or not. Finally, actor A collects the responses from the database and he/she acts accordingly with the proposed DSM program.

- The Application/Web interface is shown in Figures 14-16 and is responsible for making all the interactions between the communicating entities and the Database as transparent and easy as possible.

- The EPIC network emulator, which we have developed in our laboratory. It is a testbed using the Emulab [27] architecture and software. By adopting Emulab in EPIC, we can automatically and dynamically map physical components (e.g., servers and switches) to a virtual topology. In other words, the Emulab software configures the network topology automatically, which it is the communication channel between the main entities in our DSM case study. The main advantages are total controllability of our experiments and the easy/transparent alteration of the network topology. A web interface of the EPIC infrastructure is depicted in Figure 18. 


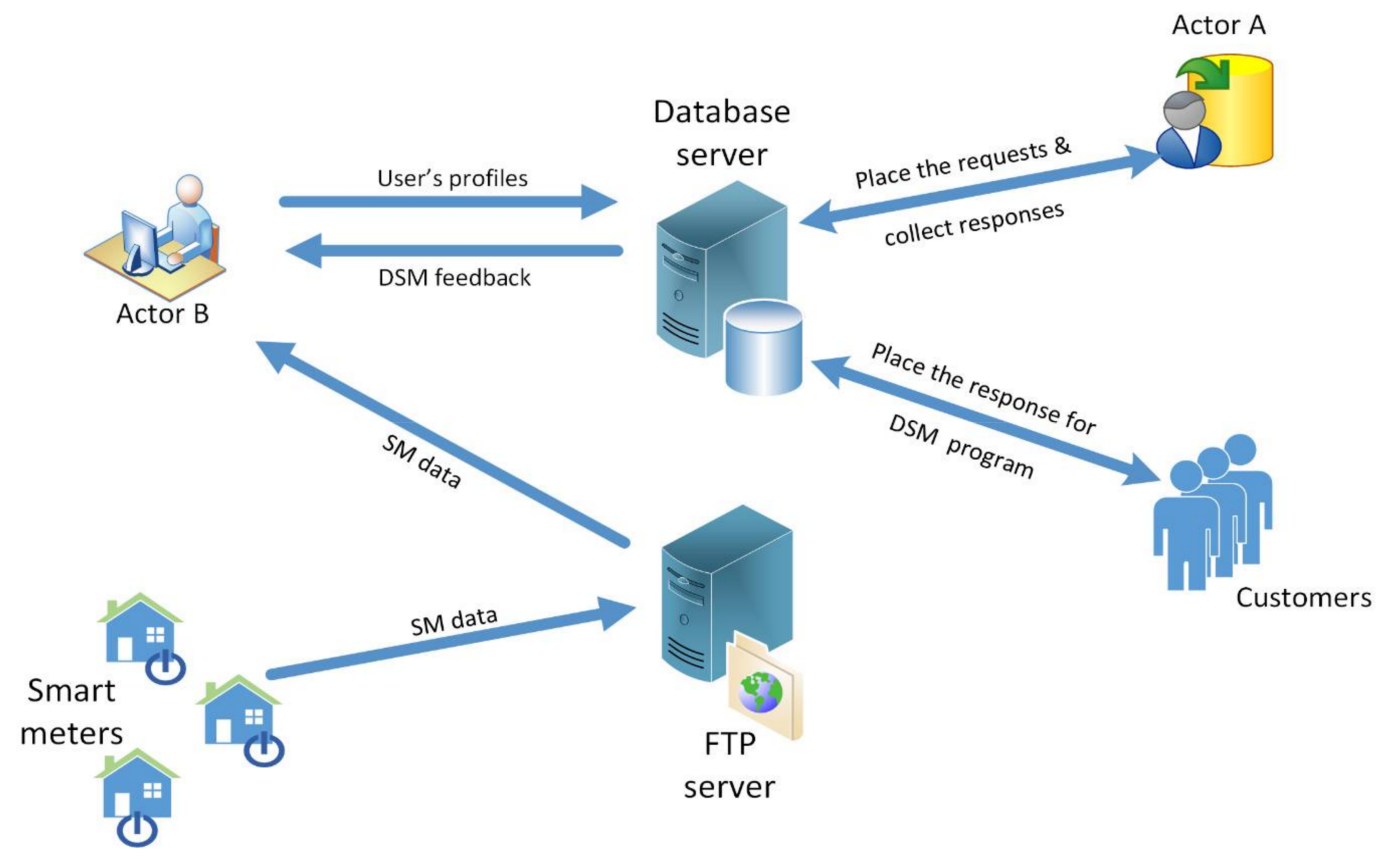

Figure 17. IT network architecture and main software elements of DSM program.

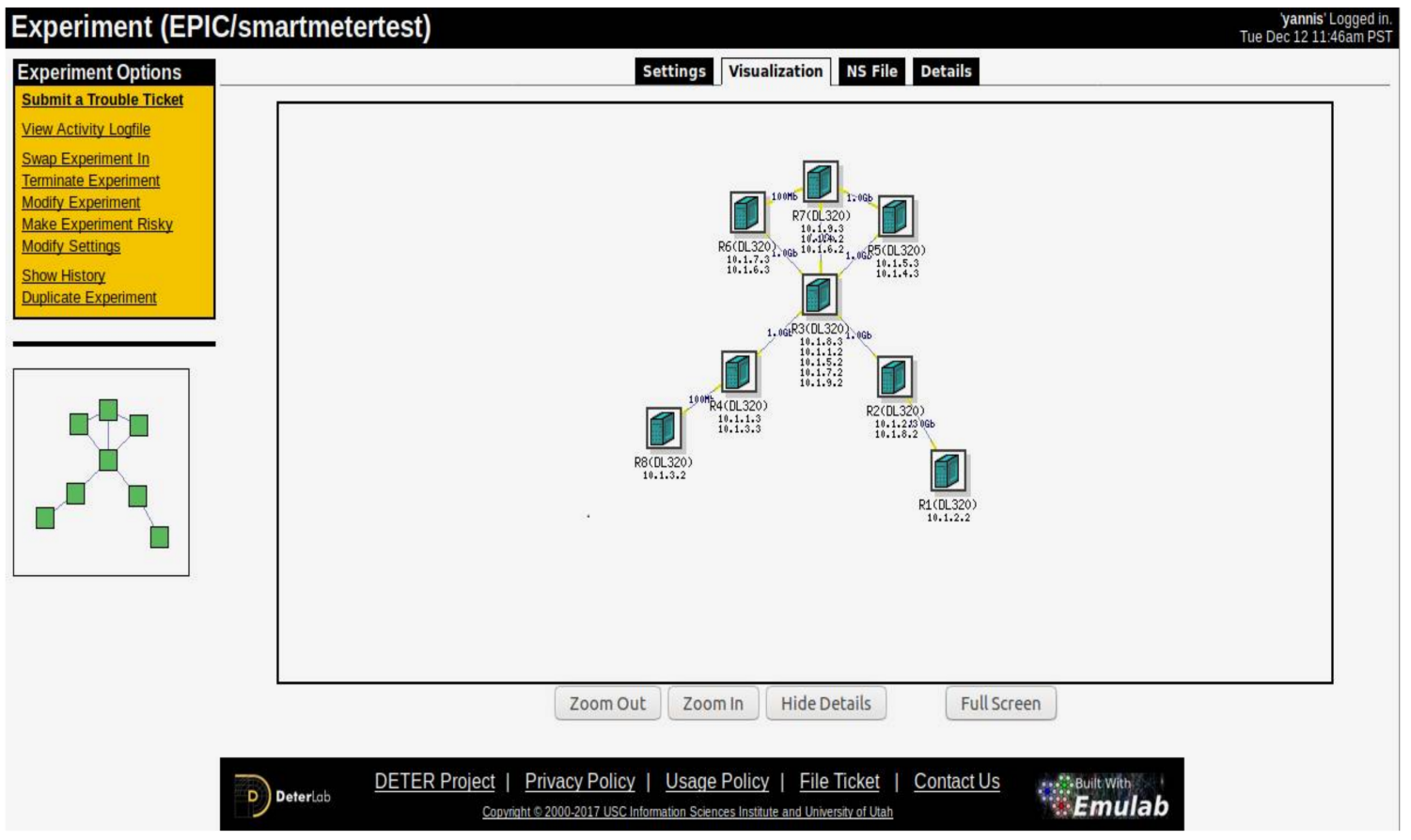

Figure 18. Experimental Platform for ICT Contingencies (EPIC) web interface for creating emulated networks.

\subsection{Concept of Remote Control}

The DSM action implies that Actor A takes control of certain electrical devices in the homes upon agreement with the end-users. The concept is to shift loads out of the critical peak time slot 18:00-20:00 or to curtail consumption during this time period. However, only specific devices can be included in such a program, whereas others due to their functionality can only be controlled by the consumer and their usage is somewhat unpredictable. The devices that fit this goal can be, for example, a washing 
machine, a dish washer, and the air cooling/heating device. In our experiment, based on the electrical devices that exist in each home, it is decided that the washing machine and the air cooling/heating device can be controlled by the Actor A, for the customers that have agreed to take part in the DSM program. The terms and conditions of the DSM are explained in the contract. In this case, it is assumed that customers are aware of the fact, that in this case they agree that the consumption of their washing machine, air conditioner, and dishwasher may be shifted or curtailed with respect to the critical time period. It is also assured that no interaction is done in the middle of the cycle of the machine. However, by shifting the washing machine consumption after 20:00, there is the potential risk of getting a peak in another time slot. Therefore, it has been decided that not all homes will have a load shift through their washing machine. For this example, three home profiles have been used. It has been decided that only one home will have the washing machine shifted outside the critical time period (Home 3 for this example).

As a first step the idea is to shift the washing machine consumption outside 18:00-20:00 in case this falls in these hours for Home 3. With respect to the air cooling/heating device, the goal is to curtail the consumption with the minimum impact on the comfort of the tenants. This can be achieved if the device operates in a periodic way, switching on and off at specific moments in time. In our experiments we have set the air cooling/heating device at each home to have a periodic function every $10 \mathrm{~min}$. The device is set to be switched on for $7 \mathrm{~min}$ and switched off for $3 \mathrm{~min}$. In this way, it will be working for $70 \%$ of the time. The time intervals are indicative. For a more complete analysis, the energy curve of such a device should be analysed and the percentage of the time it will function should be computed based on this curve. Obviously, different strategies can be followed, such as setting the temperature of the cooling device one to two degrees higher and adopting a different operation time schedule (i.e., $90 \%$ of the time to be switched on). However, an in-depth analysis is outside of the scope of this exercise. Since we have three homes that participate in the program, we have determined that the air cooling devices will be working in alternate order. As a result, in the 10 min period, only two air conditioners are simultaneously active for most of the time, whereas all three homes have their air conditioners working simultaneously for only one minute.

To replicate the remote control of these two domestic devices by Actor A, we have created a program that controls two plugs within the house. It is thus assumed that we have two controllable plugs per home. The Data acquisition and Control platform has been used and has been programmed through LabView so as to transform two normal plugs into programmable ones that switch on and off at specific time periods. The platform is composed by the external chassis, an embedded controller and an input/output acquisition board. It has two relays, whereas its controller has been programmed with LabView to control these relays. We have used a terminal block to connect the internal relays with the plugs. As a result, the plugs are controlled by the platform's controller.

The plugs are programmed to switch on and off at specific moments in time. The plug that controls the air cooling/heating device is set to be always switched on outside the critical time slot. The plug that controls the washing machine for Home 3 is set to be switched on before these hours. We determined that this home has the washing machine plug turned on one after 20:00 and in particular at 20:30. It is clear that for a large number of users a more sophisticated plan should be applied but this is outside of the scope of the present work.

The two plugs have been controlled remotely by Actor A. This concept is linked to Figure 1 as follows:

- The LabView program has been applied at Actor's A point.

- The Home Automation End Device (HAED) is represented by the Data Acquisition and Control platform and its embedded controller in the house premises.

- The LabView program is set on the platform remotely with the help of a web server; thus, we are enabled to control the two plugs remotely. 
Figure 19 shows a snapshot of the program to control the electrical devices in Home 3 for the time period when the DSM program is applied. In Figure 19, relay 1 controls the air cooling/heating device, whereas relay 2 controls the washing machine. It is shown that relay no. 1 (air condition) is switched on all the time before and after the critical time period (for 64,860 s before 18:00 and 14,340 s after 20:30), whereas relay no. 2 (washing machine) is switched off between the critical time period as well as $2.5 \mathrm{~h}$ before 18:00 to assure that no interaction will be made in the middle of the device cycle. The aforementioned concept is depicted, where the air conditioning is switched on and off alternatively during 18:00-20:00, whereas the relay controlling the washing machine becomes active at 20:30.

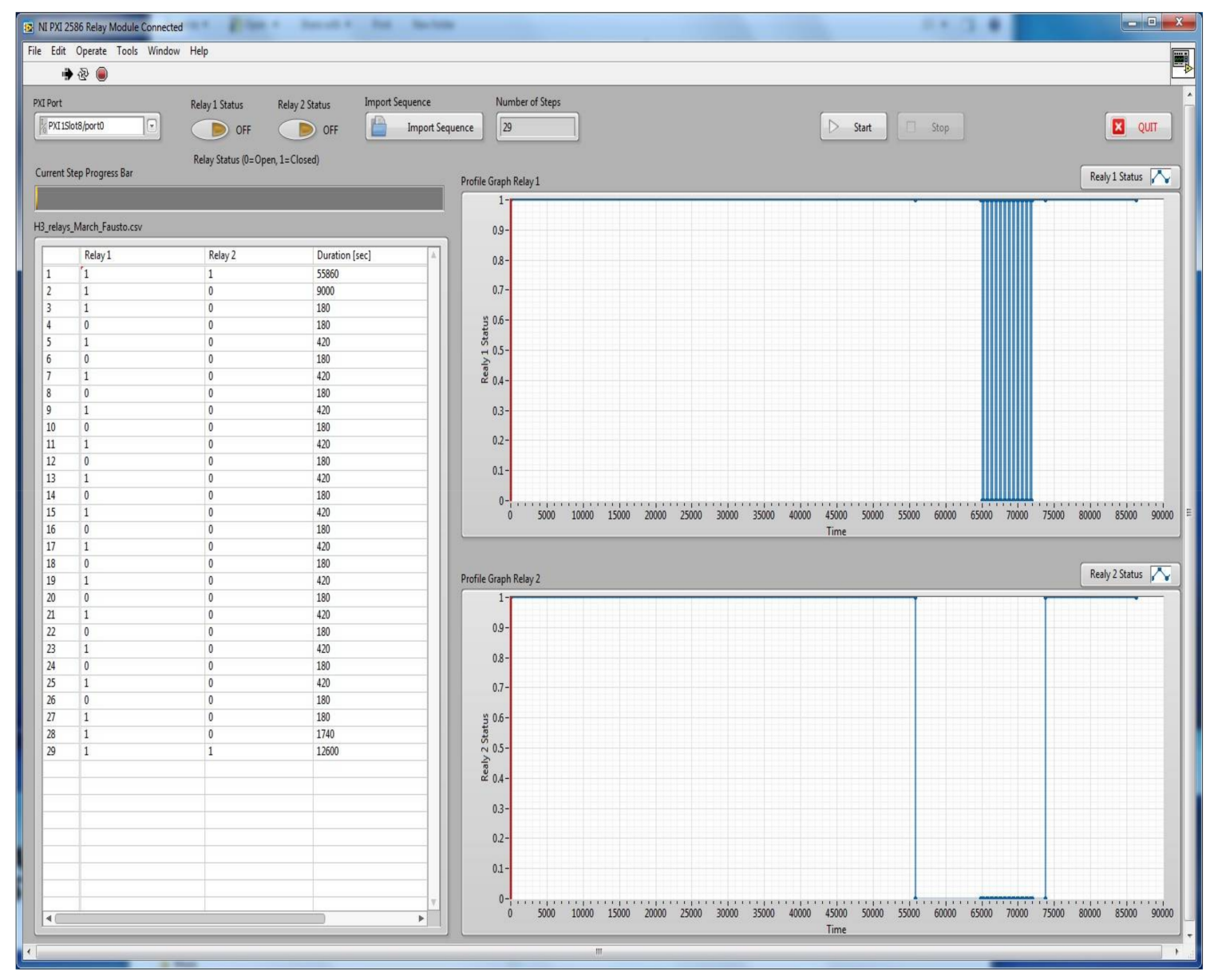

Figure 19. Program to control electrical devices within Home 3 for the critical time period.

\section{Results for Phase B of the Experiment}

After the DSM program is put in place thanks to the interaction between Actor A and the three end-users, the profiles for the examined day are measured. It is worth mentioning that, as made clear in the previous sections, the main period of interest is the peak time, 18:00-20:00. Figure 20 shows the three separated profiles after the DSM has taken place, while Figure 21 shows the aggregated curve obtained by summing them together. It should be noted at this point that for Day 2, where the DSM program is applied, three different home profiles are replicated. It is considered that Day 1 (monitoring) and Day 2 (DSM program) refer to consecutive weekdays, with the same occupancy profile (Figures 2-4). However, the electrical consumption cannot be identical. The air cooling/heating device is supposed to be functioning similarly to Day 1 . Table 2 shows its usage throughout Day 2. It should also be noticed here, that we consider one day for monitoring purposes and one day for applying the DSM program. This is a basic version of real DSM/DR programs, where different 
monitoring periods can be applied. However, the objective of this experiment is to show the main advantages of DSM/DR programs. Analysing market issues to conclude the ideal monitoring period is outside of the scope of this work.
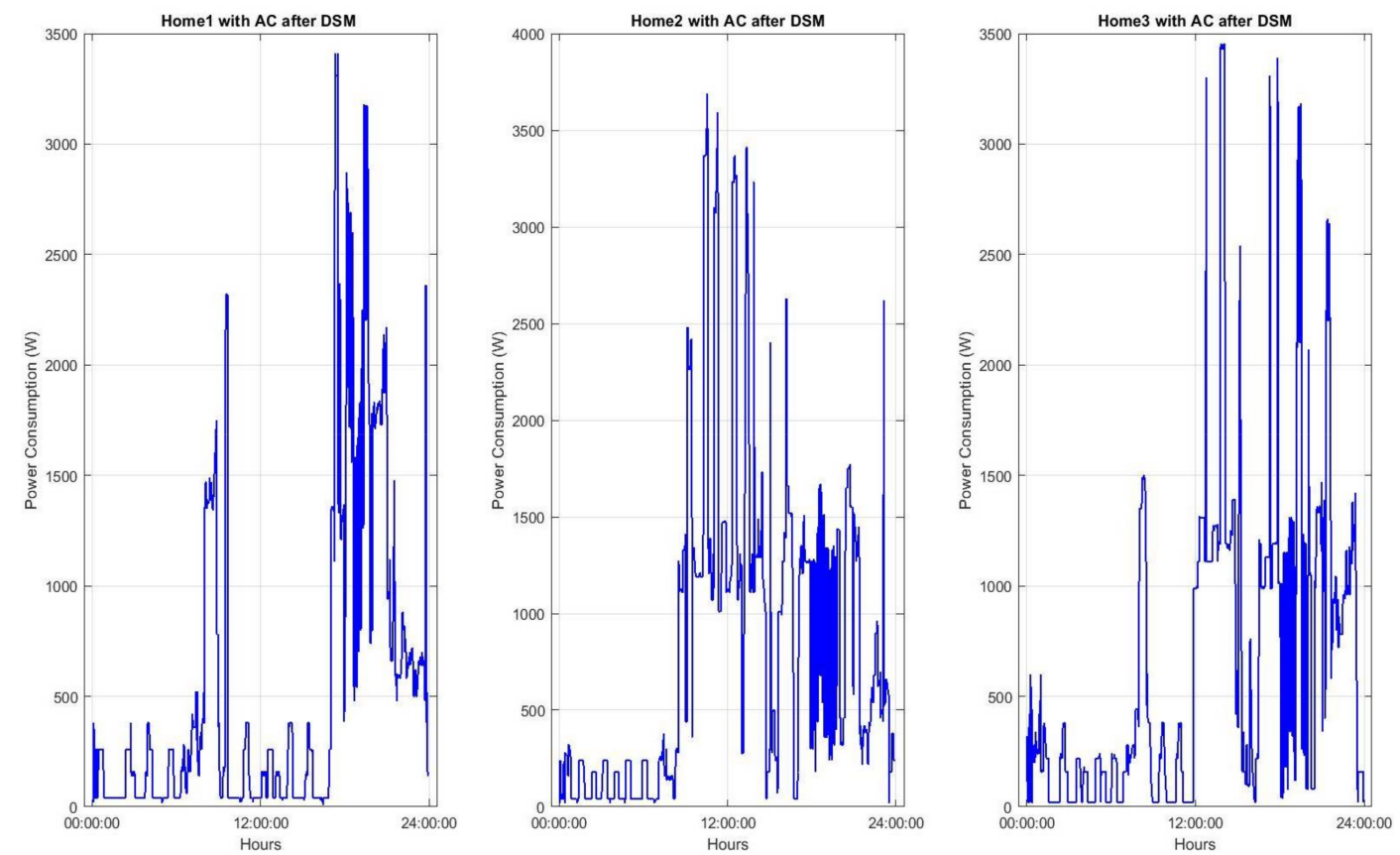

Figure 20. Snapshot of the three profiles for the day in which the DSM is put in place.

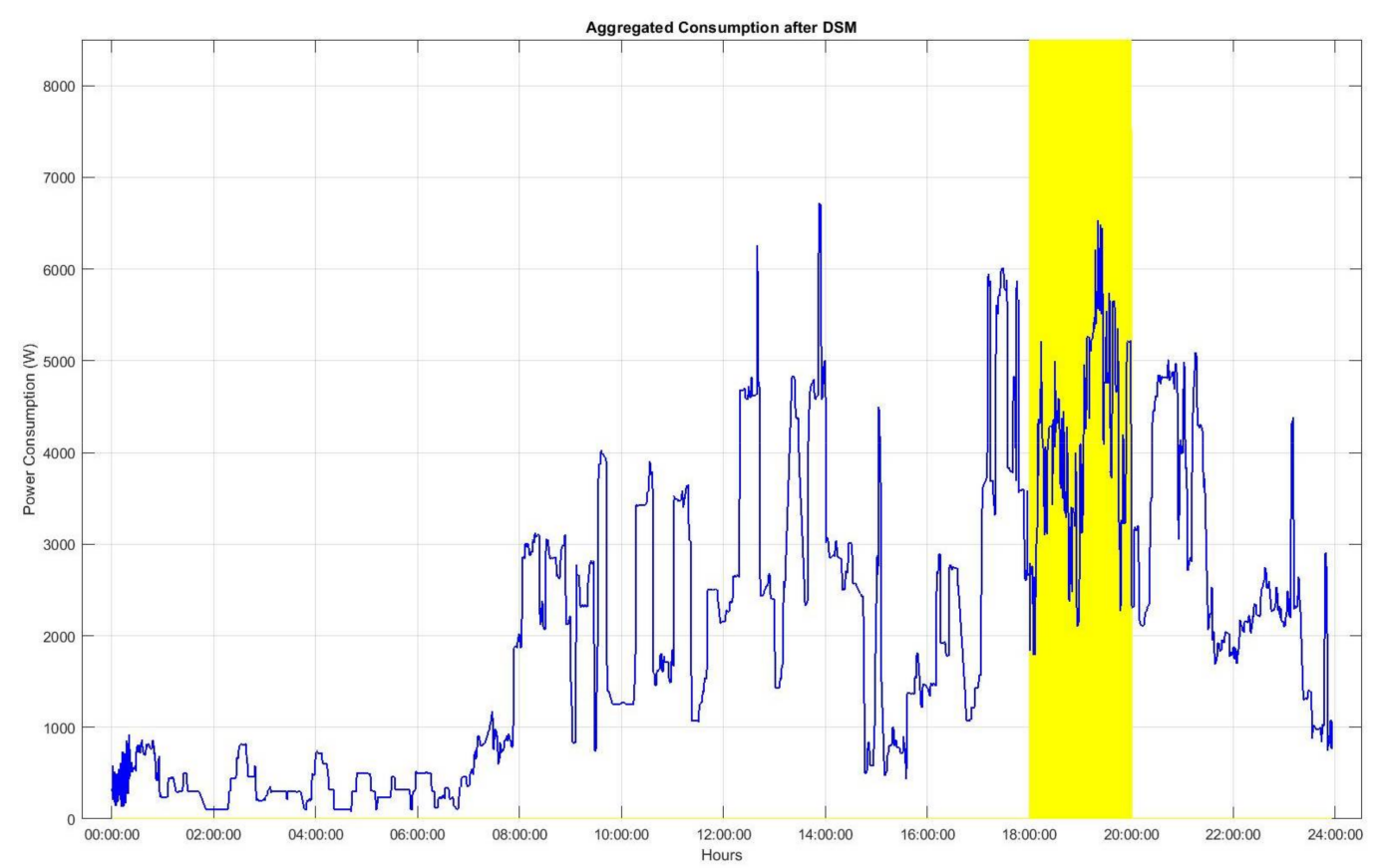

Figure 21. Snapshot of the aggregated curve for the day in which the DSM is put in place.

When comparing the new situation with the previous one, where there was no central control from Actor A, it becomes evident that in the region of interest, 18:00-20:00, the total consumption has been reduced due to the fact that smart strategies have been undertaken to provide the same level of comfort to the final users with fewer resources needed (less aggregated power needed). 
Table 2. Usage of air cooling/heating device in all homes.

\begin{tabular}{cccc}
\hline Time & Home 1 & Home 2 & Home 3 \\
\hline \multirow{2}{*}{ Morning } & $07: 46-08: 50$ & $08: 31-09: 00$ & $07: 51-08: 30$ \\
& & $09: 31-13: 00$ & \\
Afternoon & & $13: 11-14: 50$ & $11: 51-14: 50$ \\
\multirow{2}{*}{ Evening } & \multirow{2}{*}{$17: 00-21: 00$} & $17: 41-16: 20$ & $16: 31-20: 15$ \\
& & $20: 31-21: 25$ & $20: 31-21: 10$ \\
\hline
\end{tabular}

Figure 22 shows a comparison between the aggregated load consumption of the three houses after (on the left) and before (on the right) the DSM program. The two graphs are actually extracted from Figures 12 and 21; we only show the time frame between 16:00 to 22:00, since it entails the considered peak time, 18:00-20:00. As it can be observed, the aggregated load consumption in Day 1 (before the DSM program), contains peaks reaching approximately 7300 and $8000 \mathrm{~W}$. The situation is different in Day 2 (after the DSM program), where the peak between 18:00-20:00 is approximately as high as $6500 \mathrm{~W}$.
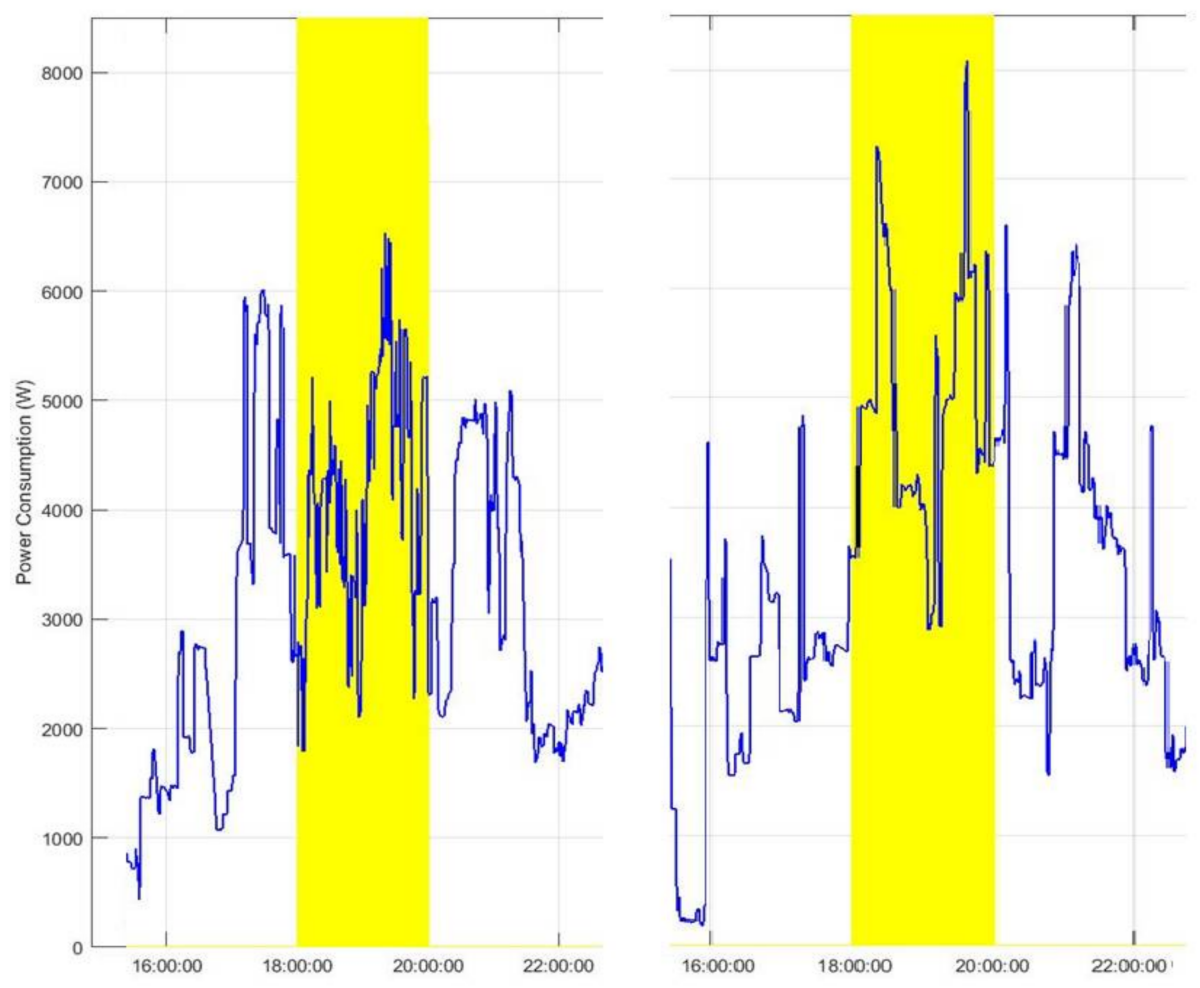

Figure 22. Comparison between after and before the DSM program for the timeframe from 16:00 to 22:00.

This shows that a smoother load curve has been achieved, which has been the objective of the DSM program. The implemented small-scale test bed entails the characteristics of a real system, such as smart meters that are used in practice; realistic domestic load curves; management of smart meter data with the OBIS specification; and remote load control that could be applied in a real home. Thus, the results obtained lead to the conclusion that DSM programs implemented in larger scale systems, can give an overall better energy management. Although the DSM program illustrated here is a basic version of what could be applied in a real use case-for instance in a city, where a large number of consumers is entailed, market parameters need to be considered and maybe a different consumption profile monitoring period is needed - the results prove the importance of DSM/DR in 
achieving better grid stability and in alleviating peaks in load consumption. This is a key aspect for grid operators, who aim at a smoother consumption curve which can result in lowering the investments for grid reinforcement.

\section{Conclusions}

In this work, a DSM program has been applied on an end-to-end system, highlighting the importance of the customers' active participation in reducing the energy consumption and showing the effect of such programs on the overall energy saving policies. The DSM program is based on the following steps: monitoring the load consumption for the duration of a day; taking decisions for the peak hours; inviting the end-users to participate in the program; applying the program the following day, provided that we deal with two weekdays or two consecutive holidays. The concept examined here consists of the basis of real complex systems, where tariff schemes are followed and a DR/DSM program is applied multiple times per day. Despite the fact that a basic DSM program is followed, the results remain of vital importance because they reveal the importance of such programs in the overall grid stability, by reducing peak consumption and managing the energy in a more efficient way. In addition, the importance of involving the end-user is shown, since it demonstrates that every customer can contribute to rendering the grid smarter. The work that has been achieved is summarized as follows:

- A small-scale end-to-end system has been realised, from end-user to energy provider.

- Multiple actors and devices are part of the system, like Actor B (which controls the metering channel), Actor A (which controls the energy channel), smart meter, data concentrator, end-user.

- Monitoring of load consumption using smart meter data has been achieved.

- A DSM management program has been put in place.

- Interaction between Actor A and the customer has taken place.

- Control of certain electric devices within the home has been done remotely.

- The consumption curve after the DSM program shows lower peaks during the critical time period, meaning that the overall objective has been accomplished.

The testbed created can be used for DR actions as well. In such cases, the consumer will be responsible for shifting/curtailing loads, after he/she is given an incentive and a hint about the peak hours of consumption. With this approach, higher energy demanding loads-such as using the oven, microwave, or hair dryer-can be shifted or curtailed.

The lab setup that has been created and tested along with the network emulation can contribute in investigating in detail the resilience and performance of similar systems, as future work. Moreover, the addition of the EPIC infrastructure has enabled the creation of realistic network topologies and conditions (e.g., delay, loss etc.) of the communication infrastructure. Based on this implementation, more advanced experiments will be created at the SGI Laboratory. We will include more customers by simulating their consumption. In addition, we will try to integrate behavioral economics studies in order to minimise the unpredictability of the customers' consumption. Moreover, this work will expand on ICT aspects by implementing main information and communication protocols. In this way we will be able to conduct experiments not only for the energy world, interoperability, and energy efficiency, but also for the ICT security and resource availability.

Acknowledgments: The work of this paper has been supported by the Joint Research Center, European Commission. The authors would also like to thank their colleagues Ioulia Papaioannou and Ioannis Poursanidis for sharing their ideas and providing fruitful conversations and comments throughout the whole duration of this project, as well as Miguel Olariaga Guardiola and Thomas Seldis for their guidance.

Author Contributions: Nikoleta Andreadou conceived and designed the experiments with the help of Giuseppe Prettico and colleagues of the Energy Security, Systems and Markets Unit (see acknowledgements section). Nikoleta Andreadou performed the experiments for Home 1 and Home 2, Day 1. Nikoleta Andreadou and Fausto Bonavitacola performed the experiments for Home 3 (Day 1), Home 1, Home 2, Home 3 (Day 2). Nikoleta Andreadou programmed the data concentrators with xml language. Nikoleta Andreadou worked with 
the smart meter rack (setting smart meter parameters, control through data concentrators). Fausto Bonavitacola programmed the LabView interface for the programmable load. Fausto Bonavitacola worked with the Data Acquisition and Control platform and programmed it with Labview so as to obtain the programmable plugs. Yannis Soupionis configured the server and set data concentrator parameters for saving the monitoring values. Ioannis Soupionis created the application/web interfaces for Actor A, Actor B and customer. Yannis Soupionis worked with the Emulab architecture and software. Giuseppe Prettico analysed the data by developing the python and Matlab scripts program and created the resulting diagrams. Nikoleta Andreadou wrote Sections 1, 2, 3.1, 4.2 and 6 and helped finalizing the paper. Giuseppe Prettico wrote Section 3.2, Section 5 and did the paper proofreading (ultimate corrections, additions). Yannis Soupionis wrote Section 4.1, contributed in Section 6 and helped finalizing the paper.

Conflicts of Interest: The authors declare no conflict of interest. The views expressed are purely those of the writers and may not in any circumstances be regarded as stating an official position of the European Commission.

\section{References}

1. Mohsenian-Rad, A.-H.; Wong, V.W.S.; Jatskevich, J.; Schober, R.; Leon-Garcia, A. Autonomous demand-side management based on game-theoretic energy consumption scheduling for the future smart grid. IEEE Trans. Smart Grid 2010, 1, 320-331. [CrossRef]

2. Sustainable Processes, CEN-CENELEC-ETSI Smart Grid Coordination Group. November 2012. Available online: ftp:/ /ftp.cen.eu/EN/EuropeanStandardization/HotTopics/SmartGrids/Sustainable\%20Processes. pdf (accessed on 16 November 2017).

3. The Potential of Electricity Demand Response, Policy Department-Economic and Scientific Policy, Directorate General for Internal Policies. May 2017. Available online: http:/ / www.europarl.europa.eu/ RegData/etudes/STUD/2017/607322/IPOL_STU(2017)607322_EN.pdf (accessed on 16 March 2018).

4. ACER Market Monitoring Report 2015-Key Insights and Recommendations, Agency for the Cooperation of Energy Regulators-ACER. November 2016. Available online: http://www.acer.europa.eu/official_ documents/acts_of_the_agency/publication/acer\%20market $\% 20$ monitoring\%20report\%202015\%20\%20key\%20insights\%20and\%20recommendations.pdf (accessed on 16 March 2018).

5. Use Case: Demand Response (DR)—Load Profile Management via Pricing Mechanisms, NIST SG Interaction Use Case Template, DGH ver. 3 8/25/08. Available online: http:/ / smartgrid.epri.com/UseCases/NIST_ SG_Interaction_use_case_DR_load_profile_price-Koch.pdf (accessed on 17 November 2017).

6. Use Case: Demand Response (DR)—Load Profile Management via Reliability Based Signals, NIST SG Interaction Use Case Template, DGH ver. 38/25/08. Available online: http:/ / smartgrid.epri.com/UseCases / NIST_SG_Interaction_use_case_DR_load_profile_reliability-Koch.pdf (accessed on 17 November 2017).

7. Use Case: Load Management with Dynamic Tariffs, Predictable and Non-Predictable Demand Reduction with Demand Shifting, Shedding and Limiting and/or On-Site Generation Capability without Local Resource Optimization, NIST SG Function Description and Use Case Template, DGH ver. 2 (Building-Centric View of Smart Grid). Available online: http:/ / smartgrid.epri.com/UseCases/NIST_SG_Load_Management_Sila.pdf (accessed on 17 November 2017).

8. Use Case: Demand Response-Utility Commanded Load Control. Available online: http:/ /smartgrid.epri. com/UseCases/DemandResponse-UtilityCommandedLoadControl.pdf (accessed on 17 November 2017).

9. Green, B.D. “Demand Response-Direct Load Control Event”, American Electric Power (AEP). Available online: http:/ / smartgrid.epri.com/UseCases/Direct\%20Load\%20Control\%20Event_ph2add.pdf (accessed on 17 November 2017).

10. The Utility Use Case \#3: Customer (Residential and Commercial) Implements Demand Response System and Responds to Demand Response Signals from the Utility (Using AMI), Version 1.11. Available online: http:/ / smartgrid.epri.com/UseCases/UC-3\%20Version\%201.11.pdf (accessed on 20 November 2017).

11. Schleichter, B. "Demand Response HAN Device Provisioning", American Electric Power (AEP). Available online: http://smartgrid.epri.com/UseCases/DR\%20HAN\%20Device\%20Provisioning_ph2add. pdf (accessed on 20 November 2017).

12. Muhammad Irfan Razzak. "DR HAN Pricing \& Event Customer Opt-Out", American Electric Power (AEP). Available online: http:/ / smartgrid.epri.com/UseCases/DR\%20HAN\%20Pricing\%20and\%20Event\% 20Customer\%20Opt_ph2add.pdf (accessed on 20 November 2017). 
13. D3.2 Overall System Requirements and Functional Specifications, Scalable Energy Management Infrastructure for Aggregation of Households (SEMIAH) Project. April 2015. Available online: http: / / semiah.eu/public-deliverables/ (accessed on 26 February 2018).

14. D4.1 Certification Mechanisms to Measure the Confidence and Reliability of the Energy Transactions, P2P SmarTest. August 2016. Available online: http:/ / www.p2psmartest-h2020.eu/deliverables (accessed on 26 February 2018).

15. Tsai, S.-C.; Tseng, Y.-H.; Chang, T.-H. Communication-efficient distributed demand response: A randomized admm approach. IEEE Trans. Smart Grid 2017, 8, 1085-1095. [CrossRef]

16. Mhanna, S.; Verbic, G.; Chapman, A.C. A faithful distributed mechanism for demand response aggregation. IEEE Trans. Smart Grid 2016, 7, 1743-1753. [CrossRef]

17. Kuzlu, M.; Rahman, M.M.; Pipattanasomporn, M.; Rahman, S. Internet-based communication platform for residential DR programmes. IET Netw. 2017, 6, 25-31. [CrossRef]

18. El-Sebaey, N.; Yousef, M.T.; El-Alayly, A.A. An application of expert system for demand side management. In Proceedings of the Fifth International Conference on Power System Management and Control, London, UK, 17-19 April 2002.

19. Shinde, P.; Swarup, K.S. Optimal Electric Vehicle charging schedule for demand side management. In Proceedings of the International Conference on Sustainable Green Buildings and Communities (SGBC), Chennai, India, 18-20 December 2016.

20. Pattanaik, P.A.; Sahoo, N.C.; Mishra, S. Implementation of demand side management using microcontroller and wireless communication. In Proceedings of the 2nd International Conference on Electrical, Computer and Communication Technologies (ICECCT), Coimbatore, India, 22-24 February 2017.

21. Paschalidis, I.C.; Li, B.; Caramanis, M.C. Demand-side management for regulation service provisioning through internal pricing. IEEE Trans. Power Syst. 2012, 27, 1531-1539. [CrossRef]

22. Sharma, I.; Bhattacharya, K.; Cañizares, C. Smart distribution system operations with price-responsive and controllable loads. IEEE Trans. Smart Grid 2015, 6, 795-807. [CrossRef]

23. Siaterlis, C.; Garcia, A.P.; Genge, B. On the use of Emulab testbeds for scientifically rigorous experiments. IEEE Commun. Surv. Tutor. 2013, 15, 929-942. [CrossRef]

24. McKenna, E.; Thomson, M. High-resolution stochastic integrated thermal-Electrical domestic demand model. Appl. Energy 2016, 165, 445-461. [CrossRef]

25. Poursanidis, I. Activities on Solar Photovoltaics and Real Time Simulation in the Smart Grid and Interoperability Laboratory of the Joint Research Centre of the European Commission- "Smart Grid Simulation" Traineeship Repor; EUR 28599 EN; Publications Office of the European Union: Luxembourg, 2017.

26. COSEM Interface Classes and OBIS Identification System, DLMS User Association, Excerpt from Companion Specification for Energy Metering. August 2013. Available online: http:/ /dlms.com/documents/Excerpt_ BB11.pdf (accessed on 23 November 2017).

27. White, B.; Lepreau, J.; Stoller, L.; Ricci, R.; Guruprasad, S.; Newbold, M.; Hibler, M.; Barb, C.; Joglekar, A. An integrated experimental environment for distributed systems and networks. In Proceedings of the 5th Symposium on Operating Systems Design and Implementation, Boston, MA, USA, 9-11 December 2002.

(C) 2018 by the authors. Licensee MDPI, Basel, Switzerland. This article is an open access article distributed under the terms and conditions of the Creative Commons Attribution (CC BY) license (http://creativecommons.org/licenses/by/4.0/). 